\title{
GEOGRAFía RELIGIOSA DEL OBISPADO \\ de Chiapas y Soconusco (1545-1821)
}

\section{Religious GeOgraphy OF THE Bishopric of Chiapas and Soconusco (1545-1821)}

\section{Juan Pedro Viqueira Albán ${ }^{1}$}

Resumen: Para poder evangelizar y administrar a los indios, las órdenes religiosas y las diócesis procedieron a dividir los territorios a su cargo en obispados, prioratos y guardianías, doctrinas y beneficios. En este artículo, buscaremos comprender las lógicas que siguieron al crear estas unidades administrativo-religiosas en el obispado de Chiapas y Soconusco durante el periodo colonial.

Palabras clave: Chiapas, historia de la Iglesia, geografía histórica, secularización de doctrinas.

Abstract: In order to evangelize and manage the Indians, the religious orders and dioceses divided the territories under their charge into bishoprics, Dominican priories and Franciscans convents, and then further into regular and secular parishes. In this article we shall try to understand their reasoning as they created these dual administrative and religious units in the bishopric of Chiapas and Soconusco during the colonial period.

Keywords: Chiapas, Catholic history, geographical history, secularization of regular parishes.

${ }^{1}$ Centro de Estudios Históricos, El Colegio de México.

Correo electrónico: viqueira@colmex.mx

Fecha de recepción: 1008 17; Fecha de aceptación: 010917.

(cc) BY-NC-ND Páginas 147-208. 


\section{Introducción}

Tras la conquista española, la Iglesia, con el fin de evangelizar y administrar espiritualmente a los indios de una manera eficaz, se esforzó por analizar y comprender las regiones en las que éstos se asentaban, para luego proceder a dividirlas de acuerdo con sus formas de organización jerárquica —obispados y prioratos, conventos y guardianías, doctrinas y beneficios- - Así, estas divisiones administrativas religiosas son la expresión territorial de los proyectos, a veces contrapuestos, de los distintos componentes de la Iglesia. En éstas podemos leer — si se estudian detenidamente - los intentos de religiosos y seculares por imponer un nuevo orden a realidades espaciales preexistentes, que tuvieron que tomar en cuenta para poder modificarlas en el sentido deseado.

Una ordenanza del Consejo de Indias con fecha de 1571, pero que al parecer repetía otra decretada con anterioridad, pedía a las autoridades americanas que procurasen, en la medida de lo posible, que las divisiones civiles y eclesiásticas coincidiesen entre sí, para facilitar su administración:

Téngase siempre intento que la división para lo temporal se vaya conformando y correspondiendo, cuanto se sufriere, a lo espiritual. Los arzobispados y provincias de las religiones con los distritos de las audiencias; los obispados con las gobernaciones y alcaldías mayores; los arciprestazgos con los corregimientos, y los curatos con las alcaldías ordinarias. $^{2}$

Sin embargo, esta política no llegó a aplicarse al pie de la letra en el istmo centroamericano, en general, ni en Chiapas, en particular.

\section{Provincias religiosas y arzobispado}

De hecho, el distrito de la Audiencia, el arzobispado y las provincias religiosas sólo llegaron a coincidir plenamente a mediados del siglo XVIII. Los límites del futuro reino de Guatemala quedaron fijados por primera vez en 1544, cuando se creó la Audiencia de Los Confines

\footnotetext{
${ }^{2}$ Fr. A. Remesal, Historia general de las Indias Occidentales ..., libro IX, cap. V, vol. II, p. 282.
} 
- cuya sede fue primero Comayagua y luego Gracias a Dios- para limitar el poder de los conquistadores que poblaban Centroamérica. Cinco años después, se ordenó el traslado de este tribunal a la ciudad de Santiago de Guatemala y empezó un proceso de convergencia algo errático entre las provincias dominicas y franciscanas con la jurisdicción de la Audiencia de Guatemala. Así, en 1551, de la provincia de Santiago Apóstol de la Orden de los Predicadores se desprendieron los conventos de Coatzacoalcos, de Tehuantepec y de todo el istmo centroamericano para integrar la provincia de San Vicente de Chiapas y Guatemala. Cuatro años después, con la reincorporación de Coatzacoalcos y Tehuantepec a la provincia de Santiago Apóstol, la coincidencia entre la provincia dominica y el territorio de la Audiencia fue total. ${ }^{3}$

Los franciscanos, por su parte, decidieron separar las custodias de San José de Yucatán y del Santísimo Nombre de Jesús de Guatemala, que comprendía desde Chiapas hasta Nicaragua, de la provincia del Santo Evangelio de México, para dar lugar, en 1559, a una nueva provincia.

Este proceso de convergencia sufrió un grave tropiezo cuando en 1564 la Corona decidió sustituir la Audiencia de Guatemala por otra con sede en Panamá. Chiapas y Soconusco pasaron, entonces, a tener como tribunal de apelación a la Audiencia de México, aunque en principio seguían sujetos al gobernador de Guatemala. A pesar de ello, al año siguiente, la provincia franciscana de Guatemala separó sus destinos de la de la Península de Yucatán. ${ }^{4}$

La convergencia se logró finalmente en 1569, cuando el rey dio marcha atrás y restableció la Audiencia de Guatemala con su territorio original. En cambio, hubo que esperar hasta 1745 para que la Audiencia de Guatemala contara con un arzobispado propio. ${ }^{5}$

Durante todo el periodo anterior, los obispados incluidos en su jurisdicción fueron sufragáneos del arzobispado de México.

\footnotetext{
${ }^{3}$ Fr. A. Remesal, Historia general de las Indias Occidentales ..., libro IX, cap. V, vol. II, pp. 282283, y cap. VI, vol. II, p. 288; P. Gerhard, Geografía histórica de la Nueva España. 1519-1821, p. 274.

${ }^{4}$ P. Gerhard, La frontera sureste de la Nueva España, p. 19.

${ }^{5}$ P. Gerhard, La frontera sureste de la Nueva España, p. 18.
} 


\section{El obispado}

Según la mencionada disposición de la Corona, el territorio del obispado con sede en Ciudad Real debía ajustarse al de la gobernación de Chiapas, que luego se convertiría en una alcaldía mayor del mismo nombre. Vale la pena señalar que, a diferencia de lo que sucedió en el centro de México, la gobernación de Chiapas no guardaba ninguna relación con algún tipo de unidad política preexistente, sino que se había conformado de manera arbitraria al resolverse las disputas entre tres grupos de conquistadores que habían incursionado en el territorio - el de Luis Marín, el de Pedro de Portocarrero, y el de Diego de Mazariegos- en favor de este último. ${ }^{6}$ Así, en su territorio, se hablaban a lo menos siete lenguas distintas, pertenecientes a tres familias diferentes. ${ }^{7}$ Los intercambios comerciales y humanos de sus distintas regiones se orientaban por lo menos de dos maneras claramente diferenciadas. Unas regiones se articulaban —a menudo conflictivamente- en torno al camino que cruzaba por el Valle del Río Grande - ahora conocido como Río Grijalva - que comunicaba el altiplano guatemalteco con el centro de México; mientras que otras miraban hacia la ruta controlada por los chontales que, por vía fluvial, iba de Honduras a Tabasco.

Por otra parte, Chiapas no conoció un proceso de fragmentación político-administrativa como el que se vivió en la Nueva Espańa en la década de $1570 .{ }^{8}$ Como resultado de esto, la alcaldía mayor de Chiapas se quedó con un territorio mucho más extenso que las alcaldías mayores del centro de la Nueva Espańa, que ciertamente estaban mucho más densamente pobladas. En principio, esto pudo haber facilitado

\footnotetext{
${ }^{6}$ Véase al respecto J. de Vos, Los enredos de Remesal; G. Lenkersdorf, Génesis histórica de Chiapas; M. H. Ruz, Los linderos del agua.

${ }^{7}$ Estas lenguas eran: zoque — de la familia mixe-zoque-; chol, tzeltal, tzotzil, tojolabal y cabil — de la familia mayanse_- y chiapaneca — de la familia oto-mangue—. No incluimos en esta lista ni al coxoh, dado que los investigadores siguen debatiendo si éste era tan sólo una variante del tzeltal (L. Campbell, The Linguistics of Southeast Chiapas, pp. 315-338; T. A. Lee, "Los coxoh", pp. 326-327.) o si, más probablemente, era la misma lengua que el tojolabal (G. Lenkersdorf, "Contribuciones a la historia colonial de los tojolabales"), ni al náhuatl, que a pesar de ser habladas por muchos miembros de las élites, no era la lengua materna de ningún pueblo de la alcaldía mayor de Chiapas (J. P. Viqueira, "Le mythe des colonies préhispaniques nahuas au Chiapas central").

${ }^{8}$ P. Gerhard, Geografia histórica de la Nueva España, pp. 13-17.
} 
la coincidencia entre la jurisdicción de la alcaldía mayor con la del obispado. Pero otros proyectos políticos la impidieron.

Originalmente, Chiapas formó parte del primer obispado que funcionó en el continente americano, el de Tlaxcala, ${ }^{9}$ y en 1536, dos años después de haberse erigido el obispado de Guatemala, Chiapas, el Soconusco, Tabasco y Yucatán se incorporaron a éste. ${ }^{10}$ Aunque el obispado de Chiapas se creó en 1539, sólo empezó a tener realidad en 1545 cuando fray Bartolomé de Las Casas llegó a Ciudad Real para hacerse cargo de él. ${ }^{11} \mathrm{Su}$ territorio abarcaba no sólo la alcaldía mayor de Chiapas, sino también el Soconusco, Tabasco, Verapaz y Yucatán. El conocido prelado había aceptado esta dignidad con el fin de seguir de cerca el experimento de la conversión pacífica de los indios de la Verapaz, que él había impulsado, y de extenderlo a otras regiones de su amplísima diócesis. Por otra parte, se proponía lograr que las Leyes Nuevas, de las cuales había sido uno de los principales promotores, se aplicaran con todo rigor en su jurisdicción.

Sin embargo, los gravísimos enfrentamientos que fray Bartolomé tuvo con los españoles de Ciudad Real y el más que mitigado apoyo que recibió de las autoridades, tanto civiles como religiosas, de Guatemala, le obligaron, pocos meses después, a salir de Chiapas y a renunciar a su investidura. A partir de ese momento la existencia de un obispado tan extenso, que tan bien se adecuaba al proyecto político y religioso del incansable "defensor de los indios", careció de sentido, por lo que se procedió a su desmembramiento. ${ }^{12}$ Yucatán fue erigido diócesis independiente en 1549. A petición de fray Tomás de Casillas, sucesor de fray Bartolomé de Las Casas en la silla episcopal, que se quejaba de no poder administrar convenientemente el territorio de Tabasco, éste fue separado de su diócesis el año 1561 y agregado a la de Yucatán. ${ }^{13}$

\footnotetext{
${ }^{9}$ La diócesis carolense, establecida en la isla de Cozumel en 1519, fue creada tan sólo para legitimar eclesiásticamente la conquista de la Nueva España y nunca llegó a tener a un obispo a su cabeza (P. Gerhard, Geografía histórica de la Nueva España. 1519-1821, p. 18).

${ }^{10}$ P. Gerhard, La frontera sureste de la Nueva España, p. 17.

${ }^{11}$ El primer obispo designado, el fraile Jerónimo Juan de Ortega, no aceptó la encomienda. El segundo, fray Juan de Arteaga, falleció en 1541 en la ciudad de México, antes de llegar a su diócesis (E. Flores Ruiz, La catedral de San Cristóbal de Las Casas, pp. 87-88).

${ }^{12} \mathrm{~J}$. de Vos, Las fronteras de la frontera sur, pp. 41-43.

${ }^{13}$ M. H. Ruz, Chiapas colonial: Dos esbozos documentales, pp. 31-32.
} 
Casi al mismo tiempo, Verapaz fue también erigido obispado independiente, mientras que el Soconusco, codiciado por su riqueza cacaotera, se incorporó a la jurisdicción episcopal de Guatemala. ${ }^{14}$ Sin embargo, la coincidencia territorial que se alcanzó en ese momento entre el obispado y la alcaldía mayor de Chiapas no habría de durar muchos años.

En 1592 el prelado de Ciudad Real, fray Andrés de Ubilla, logró que el Soconusco volviera a ser parte de su jurisdicción. ${ }^{15}$

\section{Prioratos, guardianías y beneficios}

Los prioratos y las vicarias dominicas ${ }^{16}$

Aunque las huestes conquistadoras vinieron acompañadas de algunos capellanes y de que luego, en 1537, unos religiosos mercedarios fundaron un convento de su orden en Ciudad Real, ${ }^{17}$ la evangelización de los indios de Chiapas solamente principió con la llegada de los frailes dominicos que fray Bartolomé de Las Casas trajo con él desde España en 1545. Éstos, dada la hostilidad con la que fueron recibidos por los vecinos españoles de Ciudad Real, tuvieron que buscar otros asentamientos a partir de los cuales pudieran trabajar en la conversión de los naturales. ${ }^{18}$ Fuera de los cinco religiosos y un lego que partieron al Soconusco y a la Verapaz, los demás dominicos se distribuyeron en las tres

${ }^{14}$ P. Gerhard, La frontera sureste de la Nueva España, pp. 17-18.

${ }^{15}$ F. Orozco y Jiménez, Documentos inéditos de la historia de la Iglesia en Chiapas, vol. II, pp. 25-37; M. H. Ruz, Chiapas colonial: Dos esbozos documentales, pp. 46.

${ }^{16}$ Los prioratos dominicos eran conventos que tenían a su cabeza a un prior, elegido directamente por sus miembros y luego confirmado por el provincial de la orden. Las vicarías, por su parte, eran conventos más pequeños, en los que, dado el limitado número de religiosos adscritos a él, su superior —el vicario- era designado directamente por el provincial (D. Ulloa, Los predicadores divididos, pp. 302-303).

${ }^{17}$ Los mercedarios, a pesar de que permanecieron en Chiapas durante todo el periodo colonial, nunca tuvieron a su cargo doctrina alguna de indios. Al parecer su acción se redujo a dar algunos servicios religiosos a los espańoles de Ciudad Real y a recoger limosnas por toda la provincia para causas diversas, entre la que destacaba la redención de cautivos cristianos en manos de infieles (M. C. León Cázares, "Los mercedarios en Chiapas. ¿Evangelizadores?”). Sobre las limosnas que estos frailes recababan en los pueblos de indios véase, J. P. Viqueira, Encrucijadas chiapanecas, pp. 159-173.

${ }^{18}$ Fr. F. Ximénez, Historia de la provincia de San Vicente de Chiapa y Guatemala de la orden de predicadores [1999], libro II, cap. XLIII, y XLIV, vol. I, pp. 348-355. 
principales ciudades indias de la región central: Chiapa, Copanaguastla y Zinacantán. ${ }^{19}$ Esta decisión habría de resultar de lo más acertada.

En efecto, la temprana conversión al cristianismo de los caciques de estos centros urbanos facilitó grandemente la propagación de la nueva fe, gracias a la autoridad y prestigio que estos dirigentes poseían sobre las poblaciones vecinas.

Además, el hecho de que en cada una de estas ciudades se hablara una lengua distinta permitió a los frailes en su conjunto dominar en poco tiempo tres de las cuatro lenguas de mayor difusión en la alcaldía mayor. La cuarta lengua, el zoque, no tardó en ser objeto de atención para los predicadores, que enviaron en 1546 a dos de ellos al noroeste de Chiapas con el fin de que la aprendieran y llevaran a esa región la palabra del nuevo dios. ${ }^{20}$ La evangelización de las inmediaciones de la Selva Lacandona, que seguían escapando en buena medida al dominio español, y del extremo sureste del valle del Río Grande, fueron dejadas para más adelante.

Esta primera división de tipo operativo constituyó la base de la futura ordenación territorial de los conventos dominicos en Chiapas. Así un primer convento dominico fue erigido en 1546 en Zinacantán. ${ }^{21}$ $\mathrm{Al}$ año siguiente, al mejorar las relaciones entre colonos y religiosos, éste se trasladó a Ciudad Real. ${ }^{22}$ La todavía floreciente ciudad de

${ }^{19}$ Fr. A. Remesal, Historia general de las Indias Occidentales ..., libro VI, cap. VI, vol. I, pp. 463464; Fr. F. Ximénez, Historia de la provincia de San Vicente de Chiapa y Guatemala de la orden de predicadores [1999], libro II, cap. XLVII, XLVIII, y XLIX, vol. I, pp. 360-368.

${ }^{20}$ Fr. A. Remesal, Historia general de las Indias Occidentales ..., libro VII, cap. XVIII, vol. II, p. 95; Fr. F. Ximénez, Historia de la provincia de San Vicente de Chiapa y Guatemala de la orden de predicadores [1999], libro II, cap. LIV, vol. I, pp. 380-383.

${ }^{21}$ Fr. A. Remesal, Historia general de las Indias Occidentales ..., libro VII, cap. XXI, vol. II, pp. 110-111. El término "convento" tiene dos acepciones que pueden dar lugar a confusión. Por una parte, es la casa en la que tienen su residencia fija o pasajera los frailes. En este sentido prácticamente todos los pueblos de Chiapas tuvieron su convento. Por otra parte, puede significar la sede de un priorato o de una vicaría bajo las órdenes del cual se encontraban territorios más o menos extensos. Aquí utilizaremos la palabra con este último significado.

${ }^{22}$ Fr. A. Remesal, Historia general de las Indias Occidentales ..., libro VIII, cap. II, vol. II, p. 138. 
Copanaguastla, ${ }^{23}$ en cuyas cercanías se había encontrado un poco de oro, tuvo el privilegio de ser la sede de una segunda casa dominica a partir del año 1557.

En 1564 se envío a dos religiosos de la Orden de los Predicadores a la próspera y poblada provincia de Los Zoques para que, dada su lejanía de las otras casas dominicas, residieran permanentemente ahí. ${ }^{24}$ Los frailes escogieron como centro para sus trabajos misioneros el pueblo de Tecpatán, en el cual unos seis años después se erigió un nuevo convento que tendría a su cargo toda aquella provincia. ${ }^{25}$

A este convento siguieron en 1576 el de Chiapa de Indios y el de Comitán, pueblos en los que los frailes dominicos habían empezado a adquirir algunas tierras, que serían la semilla de sus grandes y florecientes haciendas. ${ }^{26}$

${ }^{23}$ Fr. A. Remesal, Historia general de las Indias Occidentales ..., libro X, cap. IV, vol. II, pp. 387388. En 1628, esta vicaría obtuvo el rango de priorato (Fr. F. Ximénez, Historia de la provincia de San Vicente de Chiapa y Guatemala de la orden de predicadores [1999], libro IV, cap. LXI, vol. II, p. 157), aunque al año siguiente se empezaron los preparativos para trasladar su sede a Socoltenango (Fr. F. Ximénez, Historia de la provincia de San Vicente de Chiapa y Guatemala de la orden de predicadores [1999], libro IV, cap. LXIII, vol. II, p. 157).

Sobre las minas de Copanaguastla, véanse algunas referencias dispersas en: Fr. F. Ximénez, Historia de la provincia de San Vicente de Chiapa y Guatemala de la orden de predicadores [1999], libro II, cap. XLVIII, vol. II, p. 363; M. H. Ruz, Copanaguastla en un espejo, pp. 60-62; J. de Vos, La batalla del sumidero, p. 141, y Vivir en frontera, p. 91.

${ }^{24}$ Fr. A. Remesal, Historia general de las Indias Occidentales ..., libro X, cap. XVIII, vol. II, pp. 466-467.

${ }^{25}$ Fr. A. Remesal, Historia general de las Indias Occidentales ..., libro XI, cap. II, vol. II, p. 520, y cap. IV, vol. II, p. 528. Remesal da dos fechas para la fundación de esta casa: 1570 y 1572.

${ }^{26}$ En 1582, la vicaría de Chiapa de Indios fue elevada al rango de priorato: Fr. A. Remesal, Historia general de las Indias Occidentales ..., libro XI, cap. IV, vol. II, p. 532, y cap. V, vol. II, p. 538. Remesal da dos fechas distintas para la fundación del convento de Comitán: 1576 y 1582. Ello se debe a que después del pleito que los dominicos tuvieron con el alcalde mayor por los excesivos servicios y derramas que exigían a los indios de Comitán, los religiosos predicadores abandonaron su convento en 1582 . Pero ante la amenaza de que la vicaría pasara a ser administrada por los franciscanos, los dominicos regresaron a Comitán el mismo año de 1582 (G. Lenkersdorf, "La fundación del convento de Comitán").

En 1615, la vicaría de Comitán se convirtió en priorato (Fr. F. Ximénez, Historia de la provincia de San Vicente de Chiapa y Guatemala de la orden de predicadores [1999], libro IV, cap. XLVI, vol. II, pp. 128).

Sobre los inicios de las haciendas dominicas de la región de Comitán, véase M. H. Ruz, Savia india, floración ladina, pp. 59-80. 
En 1578 se erigió el convento de Oxolotán en territorio de la alcaldía mayor de Tabasco, aunque tenía a su cargo dos pueblos de Chiapas: Amatán e Ixtapangajoya. Esta casa tuvo una vida muy agitada: para empezar, a los dos años de fundada fue agregada al convento de Tecpatán. ${ }^{27}$

Para consolidar la administración de los pueblos de habla tzeltal del norte de la alcaldía que habían sido reducidos tardíamente, se crearon primero dos vicarías en 1576, en Chilón y Ocosingo, que luego se fusionaron para dar lugar al priorato de Ocosingo, en algún momento que no hemos logrado precisar entre 1595 y $1607 .{ }^{28} \mathrm{El}$ haber privilegiado Ocosingo sobre Chilón obedeció con toda seguridad al hecho de que el valle en que se ubica el primer pueblo ofrecía condiciones inmejorables para el desarrollo de las haciendas ganaderas y de las plantaciones azucareras de los hermanos predicadores.

En 1629, dadas las continuas y mortíferas epidemias que habían reducido Copanaguastla a su mínima expresión y que habían puesto fin a su antigua prosperidad, los dominicos trasladaron la sede del convento al cercano pueblo de Socoltenango, en el pie de monte de la meseta central, al abrigo de las cálidas y malsanas ciénagas del valle del Río Grande. ${ }^{29}$

${ }^{27}$ Fr. A. Remesal, Historia general de las Indias Occidentales..., libro XI, cap. IV, vol. II, pp. 533-534.

${ }^{28}$ Sobre estas primeras vicarías, véase Fr. A. Remesal, Historia general de las Indias Occidentales ..., libro XI, cap. IV, vol. II, p. 532. El priorato de Ocosingo no aparece todavía mencionado en el informe de 1595 enviado a España por el obispo fray Andrés de Ubilla (AGI, Guatemala, 161, exp. 13 (2), 2 ff. Memoria de los pueblos y beneficios que hay en el obispado de Chiapas y lo que tienen los clérigos y frailes) [1595]. En 1607, el convento ya existía dado que su prior fue definidor del capítulo dominico de ese año (Fr. A. Remesal, Historia general de las Indias Occidentales ..., libro XI, cap. XXI, vol. II, p. 646).

Curiosamente, en el informe del deán de la catedral de 1611, la región que dependía del convento de Ocosingo aparece consignada con el nombre de "Vicaría de Los Zendales" (AGI, México, 3102, exp. 1, ff. 40-47. [Informe de don Fructus Gómez, deán de la catedral de Chiapas]. Ciudad Real, 1 de octubre 1611).

Según Fr. F. Ximénez, Historia de la provincia de San Vicente de Chiapa y Guatemala de la orden de predicadores [1999], libro IV, cap. LXI, vol. II, p. 157, en 1626, los pueblos de Los Zendales volvieron a depender de Ciudad Real y Ocosingo quedó tan sólo como vicaría. Sin embargo, para mediados del siglo XVII, Ocosingo vuelve a ser mencionado con el rango de priorato (AHDSC, Fondo diocesano, carpeta 4585, exp. 3, ff. 10-12. Carta del señor obispo al señor presidente de Guatemala. Ciudad Real, 20 de julio 1659); AGCA, Guatemala, A.3.2, leg. 825, exp. 15207, ff. 3v y ss.

${ }^{29}$ M. H. Ruz, Copanaguastla en un espejo, p. 258. 
La región limítrofe de habla zoque entre Chiapas y Tabasco siguió planteando a los dominicos grandes problemas de organización. Para 1632 los pueblos que habían dependido del convento de Oxolotán habían pasado a formar parte del priorato de Ciudad Real, que vio así desbordar su jurisdicción más allá de los límites de la alcaldía mayor de Chiapas. ${ }^{30}$ En 1659 el área había recobrado algo de autonomía y había alcanzado el rango de vicaría, aunque bajo la dependencia del convento de Ciudad Real. ${ }^{31}$ Probablemente la sede de la vicaría se hallaba para entonces en Tapijulapa. ${ }^{32}$ Para esas mismas fechas, toda la zona norte del priorato de Tecpatán se había separado para formar la vicaría de Chapultenango, pueblo que tenía una ubicación comercial estratégica ya que se encontraba entre las tierras frías, productoras de grana, y las tierras bajas, ricas en plantaciones de cacao. ${ }^{33}$

Por lo general, los dominicos buscaron incluir en cada uno de sus prioratos o vicarías nichos ecológicos distintos y complementarios. Así

\footnotetext{
${ }^{30}$ Fr. A. Remesal, Historia general de las Indias Occidentales..., libro XI, cap. IV, vol. II, pp. 533534; M. H. Ruz, Un rostro encubierto ..., p. 154.

${ }^{31}$ AHDSC, Fondo diocesano, carpeta 4585, exp. 3, ff. 10-12. Carta del señor obispo al señor presidente de Guatemala. Ciudad Real, 20 de julio 1659.

${ }^{32}$ Los dominicos embrollaron aún más las cosas haciendo creer que las cinco doctrinas que antes habían constituido el convento de Oxolotán — Jalapa, Tacotalpa, Tecomajiaca, Tapijulapa y el mismo Oxolotán - eran una sola, lo que les permitía solicitar una única licencia al obispo de Yucatán. La cabecera de esta tan peculiar "doctrina” se cambió primero a Tapijulapa y posteriormente a Tacotalpa. El fraude fue descubierto cuando al trasladarse la sede de los poderes civiles de Tabasco a ese pueblo, los dominicos quisieron también administrar a los españoles, mestizos y mulatos que se asentaron en él (M. H. Ruz, Un rostro encubierto ..., p. 157, y nota 216 -p. 176-; P. Gerhard, La frontera sureste de la Nueva España, p. 33.

${ }^{33}$ Las referencias que hemos encontrado a esta vicaría son bastante escasas: AHDSC, Fondo diocesano, carpeta 4585, exp. 3, ff. 10-12. Carta del señor obispo al señor presidente de Guatemala. Ciudad Real, 20 de julio 1659; y Fr. F. Ximénez, Historia de la provincia de San Vicente de Chiapa y Guatemala de la orden de predicadores [1999], libro VI, cap. XLVI, vol. IV, p. 183.

Esta vicaría no aparece mencionada en un informe realizado por los jueces reales en 1663, pero no puede descartarse que sea tan sólo porque no alcanzaba la categoría de priorato, como era el caso de las demás casas (AHDSC, Fondo diocesano, carpeta 4792, exp. 8, 7 ff. Certificación del escribano real comprensiva del tanto que cada pueblo de esta provincia ha pagado de tributo. Ciudad Real, 1663). La amplitud y belleza de la iglesia colonial y del convento anexo no dejan lugar a dudas, sin embargo, de la importancia que este pueblo tuvo en la organización dominica (véase el trabajo de E. Hernández Pons, El convento dominico de Chapultenango, Chiapas).

Ver Cuadro 1. "Prioratos, guardianías y beneficios del obispado de Chiapas y Soconusco (1595-1705)".
} 
los prioratos de Comitán y de Socoltenango — antes de Copanaguastla-integraban áreas del fondo del Valle del Río Grande y de la vertiente sur del Macizo Central. Los prioratos de Ciudad Real, Tecpatán y Ocosingo estaban todos conformados por una gran diversidad de paisajes humanos de los que provenían productos sumamente diversos. Las sedes de sus conventos se ubicaron bien en los centros del poder político —Ciudad Real—, en puntos clave de las principales rutas de comercio - Copanaguastla, Chiapa y Tecpatán- o finalmente en lugares favorables para la fundación de grandes haciendas agrícolas o ganaderas —Chiapa, Copanaguastla, Comitán y Ocosingo-. A su vez, la presencia de un convento aumentaba la importancia comercial y política de los asentamientos en los que se establecían.

Esta compleja organización territorial construida pacientemente por los dominicos, que buscaba responder a requerimientos a menudo contradictorios, fue trastocada cuando, en 1705, el papa promulgó una bula por la que mandaba que se suprimieran todos los conventos que tuviesen menos de ocho religiosos. Lógicamente, los que desaparecieron fueron aquellos que se encontraban asentados en pueblos que ofrecían menos atractivos económicos o políticos. Así el convento de Socoltenango tuvo que agregarse al de Comitán; el de Ocosingo, al de Ciudad Real; y los de Chapultenango y Tacotalpa, al de Tecpatán. ${ }^{34}$ Es difícil saber qué consecuencias prácticas tuvo esta medida. El número de frailes no disminuyó y éstos siguieron viviendo en sus doctrinas. Pero al quedar más lejos de la vigilancia de sus priores, tal vez, la disciplina se haya relajado y los curas doctrineros hayan sucumbido con más facilidad a las tentaciones terrenales, entre ellas, al afán de lucro.

El haber llevado a cabo la evangelización de Chiapas, el dominar todas las lenguas de la región y el haber levantado todo un emporio económico, basado en haciendas y trapiches, permitieron a los

${ }^{34}$ Fr. F. Ximénez, Historia de la provincia de San Vicente de Chiapa y Guatemala de la orden de predicadores [1999], libro VI, cap. XLVI, vol. IV, p. 183.

La bula llegó a Guatemala en 1698, pero los dominicos lograron demorar algunos años su aplicación (Fr. F. Ximénez, Historia de la provincia de San Vicente de Chiapa y Guatemala de la orden de predicadores [1999], libro V, cap. LXXXVI, vol. III, pp. 373-374).

Ver Cuadro 1. "Prioratos, guardianías y beneficios del obispado de Chiapas y Soconusco (1595-1705)". 
dominicos controlar, durante gran parte del periodo colonial, la administración religiosa de casi toda la alcaldía mayor de Chiapas. Los territorios que cedieron a franciscanos y ministros seculares fueron así bastante reducidos.

\section{Las guardianías franciscanas}

Los franciscanos llegaron a Chiapas en 1577, invitados por los encomenderos, que buscaban contrarrestar con su presencia el poder de los frailes dominicos empeñados en lograr la disminución de las cargas que pesaban sobre los indios. ${ }^{35}$

El obispo fray Pedro de Feria, con el fin de que pudieran fundar, en 1577, un convento en Ciudad Real — cuyo titular fue San Antonio, pero al que casi siempre se le denomina de San Francisco-, les dio para su administración espiritual dos barrios de "indios mexicanos" de la ciudad — San Diego y San Antonio- y el vecino pueblo de San Felipe. Los naturales de este último poblado, incitados por los dominicos, apelaron esta decisión, pero sin mayor éxito. ${ }^{36}$ Además el prelado les encargó la administración espiritual de los pueblos del valle de Huitiupán y de sus inmediaciones, que por su lejanía de Ciudad Real habían recibido poca atención por parte de los dominicos. ${ }^{37}$ Con estos poblados

\footnotetext{
${ }^{35}$ Fr. P. Feria, "Carta de fray Pedro de Feria, obispo de Chiapas, al rey Felipe II ... (1579)"; F. Orozco y Jiménez, Documentos inéditos de la historia de la Iglesia en Chiapas, vol. II, pp. 121-124. ${ }^{36}$ M. H. Ruz, Chiapas colonial: Dos esbozos documentales, pp. 42-43; Fr. F. Vázquez, Crónica de la provincia del Santísimo Nombre de Jesús de Guatemala ..., libro II, cap. XXIX, vol. I, p. 318.

Las denominaciones de los barrios administrados por los franciscanos cambiaron con el tiempo. En 1595 se dice que administraban Mixtecos y Molino (AGI, Guatemala, 161, exp. 13 (2), 2 ff. Memoria de los pueblos y beneficios que hay en el obispado de Chiapas y lo que tienen los clérigos y frailes). En 1611, se registran como los barrios de los Mixtecos y de San Francisco Utatán (AGI, México, 3102, exp. 1, ff. 40-47. [Informe de don Fructus Gómez, deán de la catedral de Chiapas]. Ciudad Real, 1 de octubre 1611]. En 1663 ya aparecen con sus nombres actuales de San Diego y San Antonio (AHDSC, Fondo diocesano, carpeta 4792, exp. 8, 7 ff. Certificación del escribano real comprensiva del tanto que cada pueblo de esta provincia ha pagado de tributo. Ciudad Real, 1663).

Según, E. Flores Ruiz, Investigaciones históricas sobre Chiapas, p. 176, en un principio también se les dio el pueblo de Totolapa, y además "algunas veces administraron otras parroquias, pero en forma transitoria”, pero no hemos encontrado en los documentos de la época nada que permita sustentar estas dos afirmaciones, con excepción del pueblo de Bochil que mencionamos más adelante.

${ }^{37}$ M. H. Ruz, Chiapas colonial: Dos esbozos documentales, pp. 42-43; E. Flores Ruiz, "Secuela parroquial de Chiapas", pp. 39-45.
} 
los frailes menores integraron, en 1589, la Guardianía de Huitiupán, cuya cabecera estuvo en Asunción Huitiupán. ${ }^{38}$ En algún momento entre 1595 y 1611, los franciscanos recibieron el pueblo de Bochil, en el camino entre Ciudad Real y Huitiupán, seguramente para que tuvieran una casa propia en donde descansar al viajar de un punto al otro; ${ }^{39}$ pero este pueblo desapareció algunos años después, y cuando fue repoblado, su administración, al parecer, quedó en manos de los dominicos. ${ }^{40}$

\section{Los beneficios seculares}

Aunque un pequeño grupo de dominicos se instaló desde el año 1545 en el Soconusco, como el clima resultó muy difícil y malsano para ellos, lo dejaron unos meses después a pesar de que la región se encontraba en pleno auge económico gracias a sus abundantes plantaciones de cacao. Por esta razón, fueron miembros del clero secular quienes asumieron las tareas de evangelización en esta provincia y quienes ejercieron el control religioso sobre ella durante todo el periodo colonial. ${ }^{41}$

En la alcaldía mayor de Chiapas el primer pueblo indio cuya administración quedó en manos de un sacerdote secular fue Palenque. Este asentamiento fue fundado por fray Pedro Lorenzo de la Nada para congregar ahí a indios choles que había convencido de que dejaran la selva y se sometieran al dominio español. Sin embargo, a la muerte de

\footnotetext{
${ }^{38}$ P. Gerhard, La frontera sureste de la Nueva España, p. 123; Fr. F. Vázquez, Crónica de la provincia del Santísimo Nombre de Jesús de Guatemala, libro II, cap. XXIX, vol. I, p. 318.

${ }^{39}$ Bochil no aparece mencionado en el informe de fray Andrés de Ubilla de 1595 (AGI, Guatemala, 161, exp. 13 (2), 2 ff. Memoria de los pueblos y beneficios que hay en el obispado de Chiapas y lo que tienen los clérigos y frailes). En cambio, sí aparece en el de 1611, como formando parte de la Guardianía de Ciudad Real (AGI, México, 3102, exp. 1, ff. 40-47. [Informe de don Fructus Gómez, deán de la catedral de Chiapas]. Ciudad Real, 1 de octubre 1611).

${ }^{40}$ Después de 1611, la primera mención que hemos encontrado de Bochil en una lista de pueblos es de 1774, en la que se le menciona como hacienda integrante del curato de Jitotol, administrado por dominicos (M. García Vargas y Rivera, Relaciones de los pueblos del obispado de Chiapas ..., p. 25). Hemos localizado además dos cartas del año 1712 escritas desde Bochil. Es muy probable que se trate de la hacienda y no del pueblo que sin duda llevaba muchas décadas de haber desaparecido (AGI, Guatemala, 296, exp. 9, ff. 64v-65. Carta [de Juan Salvador al provisor don Miguel Romero de Arbizu]. Bochil, 28 de agosto 1712; y ff. 65-66. Carta [de Pedro de Montoya al provisor y vicario general Miguel Romero López de Arbizu]. Bochil, 28 de agosto 1712).

${ }^{41}$ Fr. A. Remesal, Historia general de las Indias Occidentales ..., libro VI, cap. VI, vol. I, p. 463, y cap. XIII, vol. II, pp. 499-502.
} 
este fraile, por el año de 1580, la orden, que no apreciaba sus métodos de evangelización y su repetida "indisciplina", no quiso hacerse cargo del pueblo y dejó que quedara bajo el control de un secular. ${ }^{42}$

En 1584, el obispo fray Pedro de Feria pidió y obtuvo de los dominicos que entregaran los pueblos del valle de Jiquipilas, recientemente congregados, a los clérigos que lo acompañaban. ${ }^{43}$ Esta región presentaba dos grandes atractivos: era paso obligado entre Chiapas y Oaxaca, y ofrecía grandes potencialidades para la ganadería, mismas que los españoles no tardaron en explotar, fundando varias estancias de ganado mayor.

En 1595 los dominicos cedieron también al obispo fray Andrés de Ubilla, tres pueblos cercanos a Palenque, dos de habla chol —Tila y Tumbalá- y uno tzeltal —Petalcingo- para que, sumados al de Palenque, se pudiese constituir un beneficio —el de Tila - lo suficientemente grande como para que su responsable pudiese vivir de sus rentas. ${ }^{44}$ Los padres predicadores se deshacían así de unos pueblos de difícil acceso, que habían sido atendidos por el rebelde fray Pedro Lorenzo, y se ahorraban el trabajo de tener que aprender una lengua mesoamericana más, el chol. Ignoraban que más adelante la región habría de conocer un importante crecimiento económico y una relativa riqueza gracias a sus plantaciones de cacao.

Éste fue, durante más de 150 años, el último territorio que la orden dominica habría de dejar escapar de su control espiritual. Con la excepción del Soconusco, bien pocas habían sido de hecho las concesiones de los padres predicadores: el valle de Jiquipilas, el de Huitiupán y la región de Tila y Palenque, tres regiones relativamente poco pobladas, donde sus habitantes habían vivido hasta antes de las reducciones en asentamientos pequeńos y dispersos, y que se encontraban en los confines de la alcaldía mayor de Chiapas. Casi podríamos decir que en la alcaldía mayor de Chiapas los dominicos habían cedido tan sólo lo que creyeron - equivocadamente- que eran las migajas del pastel.

\footnotetext{
42 J. de Vos, Fray Pedro Lorenzo de la Nada ..., p. 45.

${ }^{43}$ Fr. A. Remesal, Historia general de las Indias Occidentales ..., libro XI, cap. V, vol. II, pp. 539-540.

${ }_{44}$ J. de Vos, Fray Pedro Lorenzo de la Nada ..., p. 45; M. H. Ruz, Chiapas colonial: Dos esbozos documentales, p. 48.
} 


\section{La lógica de la conformación de prioratos, guardianías y beneficios}

Señalemos que, al establecerse la división en prioratos, vicarías, guardianías y beneficios, las órdenes religiosas y los obispos no parecen haberse preocupado demasiado por hacer coincidir estas jurisdicciones con las que manejaban las autoridades civiles. Por el contrario, fueron éstas las que, bajo el peso creciente que adquirieron las divisiones eclesiásticas, ajustaron su división en provincias, que era sumamente flexible y cambiante, a los límites mucho mejor definidos de dos prioratos dominicos —el Priorato de Chiapa, que dio lugar a una provincia civil del mismo nombre, y el Priorato de Tecpatán, al que se ajustó la provincia de Los Zoques-, de una guardianía franciscana - la de Huitiupán-y de un beneficio secular —el de Ocozocoautla y Jiquipilas.

En realidad, el propósito primordial de las distintas autoridades eclesiásticas fue que al interior de los prioratos, vicarías, guardianías o beneficios reinase una homogeneidad lingüística, en la medida en que la diversidad de idiomas y las distancias y las redes comerciales y humanas lo permitiesen. Este objetivo primordial se logró en los casos del Priorato de Tecpatán, en la vicaría de Chapultenango, y en el beneficio de Jiquipilas-Ocozocoautla, en los que se hablaba exclusivamente el zoque. De la misma manera los pueblos incluidos en el Priorato de Ocosingo eran todos habitados por tzeltales, y en los que formaban parte de la Guardianía de Huitiupán sólo se habla el tzotzil.

En otros cuatro casos, no se logró la total homogeneidad lingüística, pero se nota que éste era uno de los objetivos buscados. Así, el Priorato de Chiapa abarcó todos los pueblos de habla chiapaneca, junto con Tuxtla de lengua zoque, que se incluyó porque había sido sujeto del senorío de Chiapa y porque mantenía muy estrechas relaciones comerciales con su antigua cabecera. En el Priorato de Socoltenango - antes de Copanaguastla-, todos los pueblos eran tzeltales, salvo San Bartolomé de Los Llanos, que era de lengua tzotzil. La cercanía de este último a los demás asentamientos de ese priorato y su ubicación sobre el camino real que seguía el margen derecho del Río Grande parecen haber pesado a la hora de incluirlo en dicho priorato. Por otra parte, en dos parcialidades de Socoltenango, probablemente a raíz de una congregación tardía de finales del siglo XVI, se asentaron hablantes de tojolabal, contribuyendo 
así a la diversidad lingüística del priorato. ${ }^{45}$ En todas las doctrinas de la vicaría dominica de Tabasco predominaba el zoque, salvo en la de Jalapa que estaba compuesta por tres asentamientos chontales. ${ }^{46}$ Finalmente, el Beneficio de Tila incluía a los tres pueblos hablantes de chol y a Petalcingo de lengua tzeltal. Así, si hacemos caso omiso de los hablantes de tojolabal que llegaron a Socoltenango después de que se formó el priorato, los únicos conventos que fueron desde su inicio trilingües fueron el de Ciudad Real — tzotzil, tzeltal y náhuatl—y el de Comitán — tzeltal, coxoh y cabil. ${ }^{47}$

La puesta en práctica de la bula papal de 1705, que obligó a fusionar varios prioratos, diluyó en gran medida esta lógica que guiaba la conformación de las unidades eclesiásticas de rango intermedio. Sólo el beneficio de Jiquipilas-Ocozocoautla y la Guardianía de Huitiupán, que por distintas razones no fueron afectados por la bula, conservaron su homogeneidad lingüística.

\section{Doctrinas y curatos}

Como hemos visto, en principio, las doctrinas y curatos debían de coincidir con las "alcaldías ordinarias", es decir, con el territorio de los pueblos de indios. Sin embargo, esto que fue común en la Nueva España resultó imposible en Chiapas ya que las congregaciones que llevaron a cabo los dominicos a mediados del siglo XVI hicieron caso omiso de las realidades político-territoriales preexistentes. En la Nueva España, los pueblos de indios se establecieron con base en los altepetl o señoríos prehispánicos y, por lo tanto, mantuvieron una estructura territorial compleja. En efecto, cada pueblo de indios se componía de una cabecera —en la que se erigía la iglesia parroquial — y varios sujetos o estancias. ${ }^{48}$

En Chiapas, en cambio, la orden dominica — no sabemos si por ignorancia o intencionalmente- congregó a los indios que vivían dispersos sin tomar en cuenta a qué unidades político-territoriales

\footnotetext{
${ }^{45}$ G. Lenkersdorf, "Contribuciones a la historia colonial de los tojolabales”, pp. 70-76.

${ }^{46}$ Éstos eran Jalapa, Astapa y Juaguacapa (M. H. Ruz, Un rostro encubierto ..., p. 231; R. C. West, N. P. Psuty y B. G. Thom, Las tierras bajas de Tabasco ..., pp. 210-211).

${ }^{47}$ En caso de que el coxoh fuese una lengua distinta del tzeltal y del tojolabal, el Priorato de Comitán habría sido cuatrilingüe.

${ }^{48}$ B. García Martínez, "Microciudades al por mayor ...”.
} 
habían pertenecido, destruyendo así de raíz — salvo en muy contadas excepciones - la organización político-territorial prehispánica. Indios que habían pertenecido a varios altepetl y que incluso tras la conquista habían sido encomendados a distintos españoles tuvieron que convivir en un mismo asentamiento, aunque en barrios o parcialidades diferentes. De igual forma, indios que habían formado parte de un mismo señorío pasaron a formar parte de distintos pueblos de indios. De ahí que algunas parcialidades lleven el mismo nombre que un pueblo vecino. En algunos pocos casos —Comitán, Zapaluta y Socoltenango-, los dominicos incluso llegaron a congregar en un mismo pueblo a indios que hablaban lenguas distintas. El resultado es que en las regiones administradas por los predicadores los pueblos de indios no tenían sujetos y se componían, por lo tanto, exclusivamente de una cabecera. ${ }^{49}$ Una situación distinta prevaleció en la Guardianía de Huitiupán, administrada por los franciscanos. En efecto, cuando una parte importante de los indios que habían sido congregados en Los Altos de Chiapas lograron regresar a las tierras bajas de su valle intramontano a finales del siglo XVI y principios del XVII, los frailes les permitieron a cada grupo formar su propio y pequeño pueblo en las cercanías del convento principal. ${ }^{50}$ Es por esto que llegaron a existir cuatro pueblos con el nombre de Huitiupán: la cabecera - Asunción - y tres pequeños sujetos - Santa Catarina, San Pedro y San Andrés.

El contraste es todavía más radical si tomamos como punto de comparación el caso de la gobernación del Soconusco en donde los clérigos seculares a cargo de la región no parecen haberse tomado la molestia de llevar a cabo congregación alguna, de tal forma que muchos indios siguieron viviendo dispersos en sus cacaotales. De hecho, en el Soconusco los curatos - al igual que los partidos — guardaron una estrecha relación con las unidades político-territoriales prehispánicas. ${ }^{51}$

En Chiapas, tras las epidemias que acabaron con las dos terceras partes de los indios, y que se propagaron más rápidamente por la congregación de los naturales en asentamientos compactos, los

\footnotetext{
${ }^{49}$ J. P. Viqueira, Encrucijadas chiapanecas ..., pp. 342-347.

${ }^{50}$ L. Reyes García, "Movimientos demográficos en la población indígena de Chiapas durante la época colonial”, pp. 31-34.

${ }^{51}$ E. M. del S. Ortiz Díaz, El Soconusco y el Despoblado ..., pp. 106-121, 153-168.
} 
pueblos de indios terminaron siendo muy pequeños —en 1611, el tamaño promedio de los pueblos de la alcaldía mayor de Chiapas era de 201 tributarios -unos 663 habitantes- y la mediana se ubicaba en 157 tributarios_- ${ }^{52}$ De tal forma que un sólo pueblo difícilmente podía mantener a un cura doctrinero, además de que éstos eran muy escasos en Chiapas. Así, tanto por una razón como por la otra, los curatos de la alcaldía mayor en su mayoría englobaban varios pueblos: uno de los cuales era la cabecera y los demás los anexos. ${ }^{53}$

Es muy probable que desde el momento en el que las labores pastorales se estabilizaron, dominicos y franciscanos procedieran a distribuir entre sus miembros los pueblos pertenecientes que tenían a su cuidado para racionalizar su administración, dando lugar así a las primeras doctrinas. Todo indica que esta división se decidía al interior de cada orden religiosa, sin intervención del obispo. Además, es probable que esta división fuera en un principio bastante flexible, adecuándose al número de frailes disponibles en cada momento. Las escasas áreas en manos de clérigos, en cambio, habían sido separadas desde su creación en distintos beneficios claramente delimitados.

Las primeras sistematizaciones de las doctrinas dominicas del obispado de Chiapas, hechas con carácter institucional, fueron resultado de los esfuerzos de los obispos — a menudo apoyados por la Coronapor lograr que los religiosos reconocieran su autoridad en lo referente a la administración religiosa de los indios. En efecto, la autonomía que éstos gozaban con respecto al prelado era exorbitante. Así, por ejemplo, en 1637 los curas doctrineros llegaron a oponerse a una visita que, en nombre del obispo fray Marcos Ramírez de Prado, realizaba el clérigo don Diego Ramírez Grimaldo, impidiéndole ver los libros de cofradías de algunos pueblos a su cargo. ${ }^{54}$

Como resultado de una real cédula que mandaba que los frailes se sujetaran "a los seńores obispos ... en cuanto al oficio de curas

\footnotetext{
${ }^{52}$ AGI, México, 3102, exp. 1, ff. 40-47. [Informe de don Fructus Gómez, deán de la catedral de Chiapas]. Ciudad Real, 1 de octubre 1611.

${ }^{53}$ A mediados del siglo XVII, el promedio de pueblos que comprendía una doctrina o curato era 3.3, y la mediana se ubicaba en 3 .

${ }^{54}$ AGI, Guatemala, 161, exp. 35 (2), ff. 5-6. Auto [del visitador Diego Ramírez Grimaldo]. Huitatán, 3 de julio 1637.
} 
restrictamente", se procedió, en 1650, a agrupar los pueblos de Chiapas que estaban a cargo de los dominicos en 15 curatos. $^{55}$

Sin embargo, cuando fray Mauro de Tovar llevó a cabo su primera visita por su diócesis — seguramente en el año 1656-, descubrió que los frailes administraban los pueblos de indios sin licencia ni aprobación del Ordinario, sino tan sólo con la autorización de su superior directo en la Orden, en contra de lo prevenido por el Concilio Tridentino. Además los frailes cambiaban de pueblos, sin siquiera informarle de ello. ${ }^{56}$

En realidad, los poderes del obispo en esta materia eran, de acuerdo con el Real Patronato, bastante limitados, pero ni aun así eran acatados por los dominicos. Las propuestas para ocupar las doctrinas eran presentadas por los priores del convento al vice patrón —el presidente de la Audiencia de Guatemala, en este caso-, quien escogía a uno de la lista. La intervención del obispo se reducía a examinar al fraile presentado en "el ejercicio y administración de los Santos Sacramentos" y en la lengua de la doctrina que pretendía ocupar para ver si sus conocimientos eran suficientes y, en caso de que lo fueran, a darle la colación canónica. ${ }^{57}$

No obstante estas limitaciones, fray Mauro de Tovar empezó a denegar sistemáticamente las colaciones a los candidatos presentados, amparándose en una real cédula que ordenaba que cada sacerdote administrara como máximo a 400 almas. Según el prelado, había muchos religiosos en Chiapas que tenían a su cargo hasta 2,500 almas. El obispo no ignoraba que la real cédula no podía ponerse en práctica en Chiapas, ya que no

\footnotetext{
${ }^{55}$ Fr. F. Ximénez, Historia de la provincia de San Vicente de Chiapa y Guatemala de la orden de predicadores [1999], libro V, cap. V, vol. III, p. 46. Desgraciadamente no hemos localizado ningún documento en el que se detalle esta primera división parroquial. E. Flores Ruiz, Investigaciones históricas sobre Chiapas, p. 181; y "Secuela parroquial de Chiapas ...", pp. 16-17, juntó abundante información para escribir una historia de las parroquias de Chiapas desde la fundación del obispado hasta la Independencia, pero al parecer tampoco encontró datos sobre esta primera división parroquial.

${ }^{56}$ Sobre el pleito entre el obispo y los dominicos, véase AHDSC, Fondo diocesano, carpeta 4585, exp. 3, 16 ff.; M. H. Ruz, Chiapas colonial: Dos esbozos documentales, pp. 90-91; E. Flores Ruiz, La catedral de San Cristóbal de Las Casas ..., p. 98. Fr. F. Ximénez, Historia de la provincia de San Vicente de Chiapa y Guatemala de la orden de predicadores [1999], libro V, cap. V-VIII, vol. III, pp. 44-65, donde se proporciona la versión dominica de los hechos, versión que claro está es sumamente crítica hacia el prelado.

${ }^{57}$ A. C. Oss, Catholic colonialism ..., pp. 53-58; AHDSC, Fondo diocesano, carpeta 4585, exp. $3,16 \mathrm{ff}$.
} 
sólo no había suficientes sacerdotes para ello, sino que además ningún ministro aceptaría vivir con las obvenciones y limosnas que podrían resultar de doctrinas tan reducidas. De hecho el prelado - seguramente con pleno conocimiento de causa - recurrió además a datos demográficos abultados para reforzar así la impresión de que era imposible atender a los indios con un número tan reducido de frailes. ${ }^{58}$

En 1659, el padre provincial de los dominicos, fray Francisco Morcillo, junto con el procurador general de la orden, tuvo que negociar con el obispo una nueva división parroquial para intentar darle una salida al conflicto. Así, aun cuando el pleito no terminó ahí, fray Mauro Tovar logró ver reconocida su autoridad como pastor encargado de velar por los indios de su diócesis. El acuerdo consistió en dividir los territorios administrados por los dominicos, que incluían 82 pueblos —más otros 2 administrados desde Tabasco-, en 25 doctrinas que tendrían que ser administradas por 26 curas doctrineros y 10 ayudantes. Es decir que cada doctrina — que como hemos señalado casi siempre se componía de varios pueblos - sería administrada por un dominico - salvo la que tenía su cabecera en Chiapa de Indios, que necesitaba de dos-, con la ayuda, en ocasiones, de uno o más coadjutores. ${ }^{59}$

Para establecer la división parroquial se tomó en cuenta que los pueblos que formaran parte de una doctrina o curato estuviesen lo suficientemente cercanos los unos a los otros de tal forma que el sacerdote pudiese ocuparse con relativa facilidad de ellos. Además, era sin duda preferible que en cada parroquia se hablase una sola lengua para no tener que exigir demasiado de las habilidades lingüísticas del ministro que estuviese a su cargo. Sin embargo, hubo bastantes parroquias donde este requisito no se cumplía. Para empezar estaba el caso de Comitán -y tal vez también el de Socoltenango- donde en la misma cabecera se hablaban dos lenguas distintas, tzeltal y coxoh. ${ }^{60}$ San Bartolomé de

\footnotetext{
${ }^{58}$ AHDSC, Fondo diocesano, San Cristóbal, XI.A.4b. Respuesta del obispo. Ciudad Real, $1^{\circ}$ de agosto 1663; y carpeta 4585, exp. 3, 16 ff. En esos datos se contabilizaba a los medios tributarios como si fueran tributarios completos.

${ }^{59}$ AHDSC, Fondo diocesano, carpeta 4585, exp. 3, ff. 10-12. Carta del señor obispo al señor presidente de Guatemala. Ciudad Real, 20 de julio 1659.

Ver Cuadro 2. "Parroquias del obispado de Chiapas y Soconusco (1656-1830)".

${ }^{60}$ Señalemos que G. Lenkersdorf, "Contribuciones a la historia colonial de los tojolabales", pp. 14-26, ha puesto en duda que en Comitán se haya hablado tzeltal.
} 
Los Llanos, cuya lengua era el tzotzil, tenía como visita Ixtapilla poblada por tzeltales, aunque poco antes de su desaparición este anexo se integró a la doctrina de Soyatitán, cuya lengua era también el tzeltal. Más difícil debió de ser la tarea del fraile que administraba los barrios de Ciudad Real de Mexicanos, Tlaxcaltecas y Cuxtitali, y los pueblos vecinos de San Lucas y Totolapa, ya que tenía que saber náhuatl para atender a los primeros y tzotzil para los segundos, lenguas que no guardan ningún parecido entre sí. El franciscano encargado de administrar los barrios de San Diego, San Antonio y el pueblo de San Felipe se enfrentaba al mismo problema. Huixtán — tzotzil—, al igual que le sucedía en otros ámbitos, formaba parte de una división en la que predominaban los pueblos tzeltales - Tenejapa, Oxchuc y luego más adelante el nuevo asentamiento de San Martín, ahora conocido como Abasolo- . Finalmente, el clérigo de Tila, además del chol que se hablaba en la cabecera, tenía que dominar el tzeltal para poder administrar Petalcingo.

Así ni siquiera al delimitar unas unidades relativamente pequeñas como eran las parroquias fue siempre posible lograr una homogeneidad lingüística. La diversidad extrema de lenguas que existía en algunas regiones, las reubicaciones de poblaciones, las facilidades de comunicación entre algunos pueblos, las relaciones prehispánicas de dominio entre cabecera y sujetos, la historia de la evangelización y también las rivalidades entre regulares y seculares, obligaron a proceder de otra manera.

Aunque el obispo fray Mauro de Tovar, al establecer la división en doctrinas de los pueblos administrados por dominicos en 1659, insistió en que se trataba de un arreglo provisional que tendría que ajustarse según el número de religiosos existente en la provincia y de acuerdo con el crecimiento o disminución de los pueblos, esta división parroquial habría de revelarse de lo más duradera: una década después de la Independencia seguía en vigor, al menos en sus grandes líneas.

Dejando de lado el hecho de que varios pueblos desaparecieron por causa de las epidemias y de que algunos pocos se fundaron en el siglo XVIII, y sin darle demasiada importancia a los traslados de la cabecera de la parroquia, que seguramente obedecían a las preferencias de los frailes — tal vez basadas en las mejores potencialidades económicas de un pueblo sobre otro-, los cambios realizados antes de la Independencia 
fueron mínimos. Es más, a menudo, la partición en dos de ciertas parroquias ya existía en germen en la organización parroquial de 1659, dado que en ésta se establecía que el cura contaría con un coadjutor para administrar uno o más anexos. Así sucedió en las parroquias de Jitotol-Tapilula, Tecpatán-Quechula y Chapultenango-Ixtacomitán.

Los demás cambios que se produjeron son tan pocos que los podemos analizar rápidamente. La doctrina de Zinacantán se dividió muy pronto en dos, dando lugar a otra en Ixtapa. Con la secularización, la doctrina dominica que tenía su cabecera en el pueblo de Totolapa y que administraba varios de los barrios de Ciudad Real - Cuxtitali, El Cerrillo, Mexicanos y Tlaxcala- se desprendió de éstos para facilitar la tarea del párroco, ya que mientras en Totolapa y San Lucas se hablaba tzotzil, en los barrios predominaba el náhuatl. Con esta reorganización, el barrio de San Antonio, que era administrado por los franciscanos, también se integró a la parroquia del Sagrario. ${ }^{61}$ La decadencia y luego la desaparición de los pueblos que se encontraban en el fondo del valle del Río Grande de Chiapa, en los límites surorientales de la alcaldía mayor - Coapa, Huitatán, Coneta, Aquespala y Escuintenango-, hicieron que Chicomuselo terminara por abarcar el territorio de dos curatos vecinos, que se estaban quedando sin feligreses. Algo similar sucedió en el Soconusco con la decadencia de los pueblos que conformaban la parroquia de Cuilco y que terminaron por añadirse a la de Huehuetán.

El beneficio de Tumbalá, que incluía el muy distante pueblo de $\mathrm{Pa}-$ lenque, terminó por dar lugar a tres parroquias a principios del siglo XIX cuando se fundó Salto de Agua, a mitad camino de los dos anteriores. De igual forma, cuando las haciendas empezaron a multiplicarse en el Valle de Cuxtepeques, se creó un curato exclusivo para ellas por segregación del que tenía su cabecera en San Bartolomé de Los Llanos — ahora Venustiano Carranza.

Los únicos pueblos que representaron un quebradero de cabeza para su administración eran los que se encontraban en los límites con Tabasco: Amatán, Ixtapangajoya y Ostitán-Pichucalco. Empezaron siendo administrados desde Tabasco. Luego dos de ellos, Ixtapangajoya y

\footnotetext{
${ }^{61}$ Es probable que el otro barrio administrado por los franciscanos, el de San Diego, haya corrido con la misma suerte, aunque no disponemos de alguna fuente que nos permita asegurarlo.
} 
Ostitán-Pichucalco, se integraron a la nueva doctrina de Ixtacomitán, mientras que el tercer, Amatán, pasó a ser un anexo de Huitiupán y durante unos ańos de Jitotol.

La presencia cada vez mayor de españoles, mestizos y castas en algunos poblados también hizo necesario crear nuevas doctrinas, dedicadas exclusivamente a atender a los miembros de estas calidades. Tal parece haber sido el caso de Tuxtla y Chiapa, donde se mencionan dos doctrinas para cada pueblo, y el de la Ribera de Ixtacomitán, lugar de prósperas haciendas cacaoteras, al que se le dotó de un fraile para su administración religiosa. ${ }^{62}$

El resultado de la permanencia de la división parroquial del obispado de Chiapas y Soconusco — que no tuvo correspondencia con la evolución demográfica muy diferenciada de las distintas regiones que lo componían - es que para 1808 la disparidad de los curatos se había vuelto enorme. Así la parroquia de Chamula tenía que administrar a más de 11,000 feligreses, lo que obligó a que se nombraran varios coadjutores para asistir al cura titular. Oxchuc y San Bartolomé con más de 7,000 almas no se quedaba muy atrás. En cambio, las parroquias de Totolapa, Acala, Tapalapa, La Magdalena — luego Francisco León-, Huehuetán y Tizapa contaban con menos de 500 habitantes. $^{63}$

\section{La secularización de las doctrinas}

A pesar de la permanencia de la delimitación de las parroquias, éstas conocieron un cambio de gran importancia en su administración a partir de la década de 1760 cuando empezó el proceso de secularización de las doctrinas que estaban en manos de dominicos y franciscanos.

En realidad, el proyecto de secularizar algunas de estas parroquias tenía una larga historia. Así el obispo Marco Bravo de la Serna - 16761680 — solicitó y obtuvo de la Corona la secularización de la provincia de Los Zendales, que comprendía seis doctrinas administradas por

\footnotetext{
${ }^{62}$ Véase los nombramientos de curas doctrineros para la Ribera de Ixtacomitán, nombramientos distintos de los que se efectuaban para el curato y doctrina de Ixtacomitán y sus anexos (AHDSC, Fondo parroquial, caja 10, libro 2, Libro de registro ... (1683-1730), f. 123. Institución canónica de curato. Ciudad Real, [?] de septiembre 1697; y f. 155. Institución canónica de curato. Ciudad Real, 28 de enero 1715).

${ }^{63}$ D. Juarros, Compendio de la historia del reino de Guatemala. 1500-1800 [1981], pp. 64-65.
} 
los dominicos -Oxchuc, Cancuc, Guaquitepec, Ocosingo, Chilón y Yajalón-. Sin embargo, la Real Cédula de 8 de junio de 1680 que la ordenaba llegó a Chiapas después de la muerte del prelado, razón por la cual no se puso en práctica. ${ }^{64}$ La elección de las doctrinas de Los Zendales para este primer intento de secularización no tenía nada de azaroso. En esos años, Los Zendales eran la provincia más dinámica y prometedora de Chiapas: la población india había conocido un rápida recuperación; el Valle del Tulijá había empezado a producir cantidades importantes de cacao; y el camino que atravesaba la región para comunicar Ciudad Real con Tacotalpa —en ese momento la capital de Tabasco- tenía un tráfico muy intenso de mercancías y hombres. ${ }^{65}$

Sin embargo, el sucesor de Bravo de la Serna, fray Francisco Núñez de la Vega — 1682-1706_, de la orden de los predicadores, no entregó las doctrinas de Los Zendales a seculares, alegando que no había clérigos capaces de administrarlas. ${ }^{66}$ Aunque el obispo siguiente, Juan Bautista Álvarez de Toledo —-1708-1712_, intentó relanzar la secularización de esas doctrinas, la sublevación india que se produjo en esa región, en la que los rebeldes dieron muerte a todos los religiosos y clérigos que cayeron en sus manos, enfrió, por razones obvias, los ánimos de los seculares por hacerse de esas parroquias. Así en 1713, el rey mandó que, de momento, se hicieran cargo de ellos cuatro o cinco frailes, "los más provectos en la lengua tzeltal, literatura, manejo y experiencia de indios", sin que por eso los curas nominados perdieran su derecho a ocupar más adelante los curatos que les correspondían. ${ }^{67}$

\footnotetext{
${ }^{64}$ Los dominicos argumentaron que el obispo Bravo de la Serna, en su lecho de muerte, había pedido perdón a los dominicos por los agravios que les había causado y pidió que se destruyeran todos sus escritos contra ellos (AGI, Guatemala, 4, exp. 11, 16 ff. [Consulta del Consejo de Indias]. Madrid, 12 de mayo 1683). Véase también AGI, Guatemala, 26, exp. 4 (7), 2 ff. [Parecer del Consejo]. 27 de mayo 1680; exp. 4 (8), 2 ff. [Real cédula]. Madrid, 6 de junio 1680; 161, exp. 43 (3), ff. 2-4. [Carta del obispo Bravo de la Serna al presidente del Consejo de Indias]. Ciudad Real, 30 de abril 1679.

${ }^{65}$ Véase J. P. Viqueira, “Las causas de una rebelión india: Chiapas, 1712”, pp. 105-114.

${ }^{66}$ AGI, Guatemala, 389, exp. 1, ff. 87-88v. [Real cédula a la Audiencia de Guatemala]. Madrid, 30 de diciembre 1686.

${ }^{67}$ AGI, Guatemala, 294, exp. 23, ff. 565-569. Consulta del señor obispo de Chiapas. Ciudad Real, 9 de marzo 1713.
} 
Hubo todavía varios intentos más por secularizar algunas parroquias del obispado para lo cual se elaboraron diversos informes, sin que se llegara nunca a tomar una decisión al respecto. ${ }^{68}$

Finalmente, en 1756, el obispo fray José Vital de Moctezuma —1754-1766 - presentó la secularización de varias doctrinas como el remedio a la pobreza de la catedral y del cabildo eclesiástico. Para ello, propuso que las doctrinas que se secularizasen se constituyesen en "vicarías", cuyos ingresos se destinarían en su totalidad a mejorar los emolumentos de los prebendados. A cambio de ello, los párrocos encargados de dichas "vicarías" recibirían un sueldo fijo. Las doctrinas que se propuso secularizar fueron elegidas cuidadosamente para cumplir con el propósito de aumentar los ingresos del cabildo eclesiástico. Por ello, se trató de doctrinas que contaban con un gran número de almas y que generaban una importante riqueza: San Bartolomé de Los Llanos, Tuxtla, Oxchuc y Chamula, y los barrios de Ciudad Real. La Corona accedió a dicha petición, con la condición habitual de que sólo se llevara a cabo a medida de que falleciesen los doctrineros encargados de su administración. ${ }^{69}$

Aunque carecemos de un buen estudio sobre esta problemática en Chiapas, algunos datos recopilados por monseñor Eduardo Flores y algunas fuentes que nos proporcionan información sobre el estado de las parroquias en varias fechas permiten hacerse de una idea general del

\footnotetext{
${ }^{68}$ En 1716, el obispo Jacinto de Olivera y Pardo propuso al rey dar algunas doctrinas a clérigos seculares (AGI, Guatemala, 390, exp. 2, ff. 174v-176v. [Real cédula al obispo de Chiapas]. Corella, 9 de agosto 1719), y continuó con ese empeño hasta su muerte en 1733 (J. G. Domínguez Reyes, El bienestar de la Iglesia y el Estado ..., cap. II "La diócesis de Chiapa y el Soconusco", pp. 130-131).

En 1727 y 1728, se elaboró un extenso informe sobre esa materia (AGI, Guatemala, 375, exp. 4). A pesar de ello, el rey volvió a solicitar información en 1732 (AGI, Guatemala, 390, exp. 3, ff. 248v-251v. [Real cédula al virrey de la Nueva España]. Sevilla, 10 de septiembre 1732), y 1741 (AGI, Guatemala, 391, exp. 1, ff. 253-254. [Real cédula al obispo de Chiapas]. Aranjuez, 23 de abril 1741).

${ }^{69}$ J. G. Domínguez Reyes, El bienestar de la Iglesia y el Estado ..., cap. IV "La visita de la catedral y la conformación de las cuentas decimales”, pp. 186-194.
} 
proceso de secularización. ${ }^{70}$ Así, las tres primeras parroquias que se entregaron a clérigos seculares fueron Oxchuc, San Bartolomé de Los Llanos, Chamula, y tal vez una de las dos doctrinas de Tuxtla, que no por casualidad eran de las que contaban con una feligresía más numerosa. ${ }^{71}$

El obispo fray Juan Manuel García de Vargas y Rivera - 17701774 - continuó con el proceso de secularización. Durante su administración se secularizaron casi todas las parroquias de la Depresión Central -Acala, Chicomuselo, Valle de Cuxtepeques, Totolapa, Soyatitán, Socoltenango y Tuxtla—, región que se estaba despoblando dramáticamente y en la que se iban multiplicando las haciendas ganaderas. También se hizo efectiva la secularización de los barrios de indios de Ciudad Real. De igual manera corrieron con la misma suerte dos parroquias que se encontraban sobre el Camino Real que unía Guatemala y Nueva España pasando por Ciudad Real —-Teopisca e Ixtapa-, la de Chapultenango en la provincia de Los Zoques - en la que se encontraban prósperas plantaciones de cacao en manos de propietarios españoles-y las de Yajalón y Ocosingo en Los Zendales —en donde se estaban desarrollando algunas haciendas ganaderas.

Sin embargo, esta oleada de secularizaciones terminó por provocar un gran descontento entre muchos feligreses indios, que no vieron con buenos ojos la llegada de seculares a sus pueblos, más voraces que los religiosos y, en ocasiones, poco conocedores de la lengua local. Así, el dominico Diego Lanuza retomó la administración religiosa de la parroquia de Acala en el segundo semestre de 1772, tan sólo después de

\footnotetext{
${ }^{70}$ E. Flores Ruiz, “Secuela parroquial de Chiapas ...”, pp. 104-113. Véase también M. García Vargas y Rivera, Relaciones de los pueblos del obispado de Chiapas ...; AHDSC, Fondo diocesano, carpeta 3776, exp. 3. [1778]. Borrador del censo del obispo Polanco de 1778; D. Juarros, Compendio de la historia del reino de Guatemala. 1500-1800 [1981], pp. 65-81; e Informe de los párrocos del estado al gobierno del mismo... (1830). Agradezco la invaluable ayuda que José Gabriel Domínguez Reyes y Virginia Margarita López Tovilla me prestaron para resolver los casos dudosos de Chilón, Ixtacomitán, Ocosingo y Valle de Cuxtepeques, consultando los libros de gobierno, los libros parroquiales y diversos expedientes que se conservan en el Archivo Histórico Diocesano de San Cristóbal de Las Casas.

${ }^{71}$ AGI, México, 3102, exp. 2, 16 ff. [Carta del obispo y Cabildo de Mérida al rey]. Mérida, 14 de octubre 1766.

Véase el Cuadro 3. "Fechas de la secularización de las doctrinas del obispado de Chiapa y Soconusco (1762-1856)".
} 
un año en el que había sido reemplazado por un secular. ${ }^{72}$ De hecho, la Corona en 1776 pidió al siguiente obispo, Francisco Polanco - 17771784 - , que repusiera todas las cosas a su estado anterior. ${ }^{73}$

Aunque no sabemos si esta contraorden llegó realmente a aplicarse, lo cierto es que la secularización de las parroquias se detuvo por completo hasta el año 1788 , e, incluso tras su reanudación, su ritmo se volvió mucho más lento. Así, entre esa fecha y 1806, los clérigos seculares sólo obtuvieron tres parroquias dominicas —Zinacantán, Chilón e Ixtacomitán — y la más importante de los franciscanos — la Guardianía de Huitiupán- Por otra parte, como el número de clérigos bien preparados no era suficiente, los obispos tuvieron que recurrir en más de una ocasión a religiosos de distintas órdenes para que se hicieran cargo de las parroquias "secularizadas". ${ }^{74}$ Finalmente, los esfuerzos secularizadores parecen haberse detenido por completo en el año 1806, de tal forma que para 1856 los dominicos seguían administrando once parroquias y los franciscanos una: el pueblo de San Felipe, en las inmediaciones de Ciudad Real. En el caso de la orden de los predicadores, las parroquias que habían logrado conservar eran sus dos joyas más preciadas - Chiapa y Comitán-, asentadas en regiones en las que poseían grandes haciendas, más otras nueve parroquias en las que prácticamente todos los feligreses eran indios, ya sea hablantes de tzeltal —Cancuc y Guaquitepec_- ya sea de zoque - Copainalá, Tecpatán, Quechula, Tapalapa, Tapilula, Jitotol y Magdalena Coalpitán——. ${ }^{75}$ Sólo las Leyes de Reforma de 1859, que ordenaron la desamortización de las propiedades eclesiásticas y la disolución de las órdenes religiosas, pusieron fin al poderío de los dominicos, que hasta entonces habían logrado sostenerse en dos grandes pilares: las ricas haciendas ganaderas y la larga convivencia con los indios, basada en un profundo conocimiento de sus lenguas mesoamericanas.

\footnotetext{
${ }^{72}$ T. Obara-Saeki, Ladinización sin mestizaje ..., pp. 268-270.

${ }^{73}$ AGI, Guatemala, 935, exp. 1, 12 ff. Real cédula. San Lorenzo, 12 de noviembre 1776.

${ }^{74}$ E. Flores Ruiz, "Secuela parroquial de Chiapas ...", pp. 106-108, da varios ejemplos de frailes mercedarios, agustinos, franciscanos y dominicos que se hicieron cargo de parroquias secularizadas.

${ }^{75}$ Precisemos que la parroquia de Jitotol incluía la hacienda de Bochil, en donde se hablaba también náhuatl.
} 


\section{Reflexión final}

El ordenamiento del territorio del obispado de Chiapas y Soconusco para primero poder evangelizar a los naturales y luego administrar a los feligreses no se llevó a cabo de manera improvisada y errática. Por el contrario, las diversas autoridades religiosas —obispos, provinciales, priores y guardianes - que repartieron el territorio entre dominicos, franciscanos y clérigos seculares, que lo estructuraron en prioratos, guardianías y beneficios, y que lo dividieron en parroquias, actuaron con base en un buen conocimiento de la distribución geográfica de las lenguas mesoamericanas, de las rutas comerciales, de los caminos y de las posibilidades de desarrollo económico de las diversas regiones del obispado. Claro está que a mediano y largo plazo algunas de las previsiones que hicieron resultaron erróneas: regiones que parecían condenadas a una situación marginal, como dos de las entregadas al clero secular — Valles de Ocozocoautla y Cintalapa, y el Área Cholconocieron sus momentos de bonanza con el desarrollo de nuevas actividades productivas — ganadería y cultivo de cacao-. Otras que parecían tener un gran futuro, como la provincia de Los Zendales, se hundieron en unos pocos ańos como resultado de acontecimientos poco previsibles, como lo fue la sublevación india de 1712 y su violenta pacificación.

Como hemos visto, la división parroquial que se llevó a cabo a mediados del siglo XVII, que se acordó al calor de la disputa entre el obispo fray Mauro y Tovar y la Orden de los Predicadores y que se anunció como provisional, se mantuvo vigente en sus grandes líneas durante todo el periodo colonial e incluso más allá de éste. El esfuerzo que se hizo por conciliar objetivos contradictorios — homogeneidad lingüística de los naturales, relativa cercanía de la cabecera parroquial de sus respectivos anexos y un número suficiente de feligreses para el sostenimiento de sus párrocos - y la inercia propia de todas las instituciones hicieron posible su permanencia durante a lo menos dos siglos. El creciente desequilibrio en el número de feligreses por parroquia, resultado de una evolución demográfica muy contrastada en las distintas regiones del obispado, se resolvió, por lo general, nombrando un mayor número de coadjutores para auxiliar al párroco propietario en 
sus labores. Ése fue, por ejemplo, el caso de la vicaría de Chamula, que conoció un crecimiento demográfico prodigioso desde mediados del siglo XVIII hasta la conclusión del periodo colonial.

Finalmente, la secularización, a pesar de las dificultades y retrocesos que conoció, y a pesar de que se hizo de una manera pragmática y coyuntural - de acuerdo con las vacantes que se iban produciendo en las doctrinas-, desembocó en un curioso equilibrio entre los proyectos e intereses del obispado y los de la orden dominica. Los prelados buscaron que las parroquias más pobladas y con más futuro económico pasaran a ser administradas por clérigos seculares. La Orden de Santo Domingo, por su parte, logró que las áreas en las que tenía grandes haciendas siguieran bajo su administración —Chiapa y Comitán-. Las parroquias cuyos habitantes eran casi todos indios y que se hallaban apartadas de los grandes ejes comerciales y de las mejores tierras del obispado fueron las menos disputadas, por lo tanto los religiosos dominicos pudieron seguir administrando varias de ellas sin encontrar una oposición por parte de la diócesis. De hecho, desde principios del XIX - y en algunos casos, como el de Chamula, desde algunas décadas antes - el desencuentro entre los indios y sus párrocos fue creciendo. ${ }^{76}$ De este periodo, el Archivo Histórico Diocesano de San Cristóbal de Las Casas conserva centenares de cartas de los párrocos de las regiones más indígenas en las que se quejan que sus feligreses se niegan a darles el debido sustento, a abandonar sus costumbres paganas y a obedecer sus órdenes, a veces azuzados por los maestros de primeras letras de inspiración liberal. Estos párrocos terminaban suplicando que se les cambiara a alguna otra parroquia en las que sus esfuerzos produjeran mejores resultados. ${ }^{77}$

Las Leyes de Reforma y, después de la Revolución mexicana, la persecución religiosa terminaron por debilitar al extremo el poder de la Iglesia católica en Chiapas. ${ }^{78}$ Esta situación sólo empezó a cambiar a

\footnotetext{
${ }^{76}$ Sobre el conflicto en Chamula, véase Autos de los indios de Chamula, contra su cura.

${ }^{77}$ Este desencuentro entre los párrocos y sus feligreses ha sido estudiado por R. Ortiz Herrera, Pueblos indios, Iglesia católica y élites políticas en Chiapas ...; y J. P. Viqueira, "Amar a Dios en tierra de indios ...”.

${ }^{78}$ Sobre la persecución religiosa en Chiapas y la debilidad de la Iglesia católica en la primera mitad del siglo XX, véase J. Ríos Figueroa, Siglo XX: Muerte y resurrección de la Iglesia Católica en Chiapas ..., pp. 36-126; y M. Lisbona Guillén, Persecución religiosa en Chiapas (1910-1940) ...
} 
mediados del siglo XX, cuando se puso en marcha un nuevo proyecto evangelizador en el estado, que — sin renegar por completo de la división parroquial anterior- supuso repensar a fondo la geografía religiosa de Chiapas y crear nuevas unidades territoriales más acordes con los objetivos perseguidos, tales como la división del estado de Chiapas en tres obispados y la creación en el obispado de San Cristóbal de Las Casas de las zonas pastorales.

\section{Bibliografía citada}

Autos de los indios de Chamula, contra su cura, 1992, Gobierno del Estado de Chiapas, Universidad Autónoma de Chiapas, Universidad Nacional Autónoma de México, Grupo Editorial Miguel Ángel Porrúa, México.

Campbell, Lyle, 1988, The Linguistics of Southeast Chiapas, Mexico, New World Archaeological Foundation, Provo, Utah.

Domínguez Reyes, José Gabriel, 2016, El bienestar de la Iglesia y el Estado: La gestión episcopal de Francisco Polanco, obispo de Chiapas (1777-1784), Tesis de doctorado, El Colegio de Michoacán, México.

"Estado de curatos del arzobispado de Guatemala, 1806", Boletín del Archivo General de Gobierno (Guatemala), III: 2, enero de 1938, pp. 225-229.

Feria, Fray Pedro de, 1970 (edición facsimilar de la de 1877), "Carta de fray Pedro de Feria, obispo de Chiapas, al rey don Felipe II, remitiéndole un memorial de lo que en aquella provincia pasaba. Chiapas, 26 de enero 1579", en Cartas de Indias, Edición de Edmundo Aviña Levy, Guadalajara, vol. I, pp. 451-459.

Flores Ruiz, Eduardo, 1973, Investigaciones históricas sobre Chiapas, Patronato Fray Bartolomé de Las Casas, San Cristóbal de Las Casas, Chiapas, México.

Flores Ruiz, Eduardo, 1978, La catedral de San Cristóbal de Las Casas. 1528-1978, Universidad Autónoma de Chiapas, México. 
Flores Ruiz, Eduardo, 1985, "Secuela parroquial de Chiapas, un documento inédito", Boletín del Archivo Histórico Diocesano (San Cristóbal de Las Casas), II, núms. 2 y 3, junio.

García Martínez, Bernardo, 2011, "Microciudades al por mayor. Las congregaciones de pueblos en el siglo XVI", Arqueología Mexicana, núm. 107, pp. 66-71, enero-febrero.

García Vargas y Rivera, Manuel, 1988, Relaciones de los pueblos del obispado de Chiapas. 1772-1774, Introducción, paleografía y notas de Jorge Luján Muñoz, Patronato Fray Bartolomé de Las Casas, San Cristóbal de Las Casas.

Gerhard, Peter, 1986, Geografía histórica de la Nueva España. 15191821, Universidad Nacional Autónoma de México, México.

Gerhard, Peter, 1991, La frontera sureste de la Nueva España, Universidad Nacional Autónoma de México, México.

Hernández Pons, Elsa, 1994, El convento dominico de Chapultenango, Chiapas, Instituto Chiapaneco de Cultura, Ocozocoautla de Espinoza (Chiapas).

Informes de los párrocos del estado al gobierno del mismo sobre la situación de los pueblos, dados en cumplimiento de la orden circular de 23 de junio de 1830, Imprenta de la Sociedad a cargo del C. Secundino Orantes, 1830, San Cristóbal.

Juarros, Domingo, 1981, Compendio de la historia del reino de Guatemala. 1500-1800, Piedra Santa, Guatemala.

Lee, Thomas A., 1993, "Los coxoh”, en V. M. Esponda (compilador), La población indígena de Chiapas, Instituto Chiapaneco de Cultura, Tuxtla Gutiérrez, pp. 321-341.

Lenkersdorf, Gudrun, 1986, "Contribuciones a la historia colonial de los tojolabales", en Los legitimos hombres. Aproximación antropológica al grupo Tojolabal, M. H. Ruz (editor), Universidad Nacional Autónoma de México, México, vol. IV, pp. 13-102.

Lenkersdorf, Gudrun, 1992, "La fundación del convento de Comitán: Testimonios de los tojolabales", Estudios de Cultura Maya, XIX, pp. 291-319. 
Lenkersdorf, Gudrun, 1993, Génesis histórica de Chiapas. 1522-1532. El conflicto entre Portocarrero y Mazariegos, Universidad Nacional Autónoma de México, México.

León Cázares, María del Carmen, 1991, "Los mercedarios en Chiapas. ¿Evangelizadores?”, Estudios de Historia Novohispana, núm. 11, pp. 11-43.

Lisbona Guillén, Miguel, 2008, Persecución religiosa en Chiapas (19101940). Iglesia, Estado y feligresía en el periodo revolucionario, Universidad Nacional Autónoma de México, Instituto de Investigaciones Antropológicas, Programa de Investigaciones Multidisciplinarias sobre Mesoamérica y el Sureste, México.

Obara-Saeki, Tadashi, 2010, Ladinización sin mestizaje. Historia demográfica del Área Chiapaneca 1748-1813, Consejo Estatal para la Cultura y las Artes de Chiapas (Umbrales, 18), Tuxtla Gutiérrez, México.

Orozco y Jiménez, Francisco, 1999, Documentos inéditos de la historia de la Iglesia en Chiapas, 2 vols., Consejo Estatal para la Cultura y las Artes de Chiapas, Tuxtla Gutiérrez, México.

Ortiz Díaz, Edith María del Socorro, 2011, El Soconusco y el Despoblado. Historia de la población y de la economía de una provincia colonial de 1524 a 1790, Tesis de doctorado, El Colegio de México, México.

Ortiz Herrera, Rocío, 2003, Pueblos indios, Iglesia católica y élites politicas en Chiapas (1824-1901). Una perspectiva comparada, Gobierno del estado de Chiapas, El Colegio de Michoacán, Tuxtla Gutiérrez, México.

Oss, Adriaan C. van, 1986, Catholic colonialism. A parish history of Guatemala, 1524-1821, Cambridge University Press, Londres.

Remesal, Fr. Antonio de, 1988, Historia general de las Indias Occidentales y particular de la gobernación de Chiapa y Guatemala, 2 vols., Porrúa, México.

Reyes García, Luis, 1961, "Documentos nahuas sobre el estado de Chiapas", en Los mayas del sur y sus relaciones con los nahuas meridionales, VIII Mesa Redonda de la Sociedad Mexicana de Antropología, México, pp. 167-194. 
Reyes García, Luis, 1962, “Movimientos demográficos en la población indígena de Chiapas durante la época colonial", en La Palabra y el Hombre, núm. 21, pp. 25-48, Universidad Veracruzana, México.

Ríos Figueroa, Julio, 2002, Siglo XX: Muerte y resurrección de la Iglesia Católica en Chiapas. Dos estudios históricos, Universidad Nacional Autónoma de México, Programa de Investigaciones Multidisciplinarias sobre Mesoamérica y el Sureste, México.

Robles Domínguez de Mazariegos, Mariano, 1992, Memoria histórica de la provincia de Chiapa, una de las de Guatemala, presentada al augusto Congreso por el Br. D. Mariano Robles Domínguez de Mazariegos, canónigo de la santa iglesia catedral de Chiapa, diputado en Cortes por su provincia. Cádiz: 1813, Rodrigo Núnez Editores, Tuxtla Gutiérrez, México.

Ruz, Mario Humberto, 1985, Copanaguastla en un espejo. Un pueblo tzeltal en el Virreinato, Centro de Estudios Indígenas, Universidad Autónoma de Chiapas, San Cristóbal de Las Casas, México.

Ruz, Mario Humberto, 1989, Chiapas colonial: Dos esbozos documentales, Universidad Nacional Autónoma de México, México.

Ruz, Mario H., 1991, Los linderos del agua. Francisco Montejo y los origenes del Tabasco colonial, Gobierno del estado de Tabasco, México.

Ruz, Mario Humberto, 1992, Savia india, floración ladina. Apuntes para una historia de las fincas comitecas (siglos XVIII y XIX), Consejo Nacional para la Cultura y las Artes, México.

Ruz, Mario H., 1994, Un rostro encubierto: Los indios del Tabasco colonial, Centro de Investigaciones y Estudios Superiores en Antropología Social e Instituto Nacional Indigenista, México.

Ulloa, Daniel, 1977, Los predicadores divididos. Los dominicos en Nueva España, Siglo XVI, El Colegio de México, México.

Vázquez, Fr. Francisco, 1937-1944, Crónica de la provincia del Santísimo Nombre de Jesús de Guatemala de la Orden de nuestro padre san Francisco en el reino de Nueva España, 4 vols., Sociedad de Geografía e Historia de Guatemala (Biblioteca Goathemala, vols. XIV-XVII), Guatemala. 
Viqueira, Juan Pedro, 1995, "Las causas de una rebelión india: Chiapas, 1712", en J. P. Viqueira y M. H. Ruz (editores), Chiapas: Los rumbos de otra historia, Universidad Nacional Autónoma de México, Centro de Investigaciones y Estudios Superiores en Antropología Social, Centro de Estudios Mexicanos y Centroamericanos, Universidad de Guadalajara, México, pp. 103-143.

Viqueira, Juan Pedro, 1997, "Le mythe des colonies préhispaniques nahuas au Chiapas central”, Journal de la Société des Américanistes, núm. 83 , pp. 37-58.

Viqueira, Juan Pedro, 2002, Encrucijadas chiapanecas. Economía, religión e identidades, Tusquets, El Colegio de México, México.

Viqueira, Juan Pedro, 2007, "Amar a Dios en tierra de indios. La vida cotidiana de los párrocos de San Andrés (Larráinzar), Chiapas, 1777-1914", en P. Gonzalbo y M. Bazant (coordinadores), Tradiciones y conflictos. Historias de la vida cotidiana en México e Hispanoamérica, El Colegio de México, El Colegio Mexiquense, México, pp. 179-209.

Vos, Jan de, 1981, Fray Pedro Lorenzo de la Nada, misionero de Chiapas y Tabasco, en el cuarto centenario de su muerte, Diócesis de San Cristóbal, San Cristóbal de Las Casas, México.

Vos, Jan de, 1985, La batalla del sumidero. Antología de documentos relativos a la rebelión de los chiapanecas, 1524-1534, Editorial Katún, México.

Vos, Jan de, 1992, Los enredos de Remesal. Ensayo sobre la conquista de Chiapas, Consejo Nacional para la Cultura y las Artes, México.

Vos, Jan de, 1993, Las fronteras de la frontera sur. Reseña de los proyectos de expansión que figuraron la frontera entre México y Centroamérica, Universidad Juárez Autónoma de Tabasco, Centro de Investigaciones y Estudios Superiores en Antropología Social, Villahermosa, México.

Vos, Jan de, 1994, Vivir en frontera. La experiencia de los indios de Chiapas, Centro de Investigaciones y Estudios Superiores en Antropología Social, Instituto Nacional Indigenista, México. 
West, Robert C., N. P. Psuty y B. G. Thom, 1987, Las tierras bajas de Tabasco en el sureste de México, Gobierno del estado de Tabasco, Villahermosa, México.

Ximénez, Fr. Francisco, 1999, Historia de la provincia de San Vicente de Chiapa y Guatemala de la orden de predicadores [1999], 5 vols., Consejo Estatal para la Cultura y las Artes de Chiapas, Tuxtla Gutiérrez, México.

\section{Documentos citados}

Archivo General de Centro América (AGCA)

AGCA, Guatemala, A.3.2, leg. 825, exp. 15207. [Padrón de tributarios de la provincia de Guatemala y San Vicente de Chiapas.] [21 ff.]

Archivo General de Indias (AGI)

AGI, Guatemala, 4. Consultas originales correspondientes al distrito de la Audiencia. Años de 1680 a 1699.

AGI, Guatemala, 4, exp. 11. Consejo de Indias, a 12 de mayo de 1683. En cumplimiento del real decreto de vuestra majestad con que se sirvió remitir un memorial de fray Antonio de Molina, procurador general de la provincia de San Vicente de Chiapas y Guatemala de la orden de predicadores sobre las doctrinas de Chimaltenango y las de los Zendales, dice lo que se le ofrece [16 ff.].

AGI, Guatemala, 26. Cartas y expedientes del presidente y oidores de la Audiencia. Años de 1678-1677.

AGI, Guatemala, 26, exp. 4 (7). Acordado del Consejo de 27 de mayo de 1680 sobre lo escrito por el obispo de Chiapas acerca del obrar de los doctrineros de la provincia de Los Zendales y otras cosas [2 ff.].

AGI, Guatemala, 26, exp. 4 (8). [Real cédula. Madrid, a 6 de junio 1680] Al obispo de Chiapas que suspenda de las siete doctrinas de la provincia de Los Zendales a los religiosos que las tienen y nombre sacerdotes seculares que las sirvan en la forma que arriba se dice [2 ff.]. 
AGI, Guatemala, 161. Cartas y expedientes de los obispos de Chiapas. 1541-1699.

AGI, Guatemala, 161, exp. 13 (2). [1598] Memoria de los pueblos y beneficios que hay en el obispado de Chiapas y lo que tienen los clérigos y frailes [2 ff.].

AGI, Guatemala, 161, exp. 35 (2). [1637] Testimonio de autos sobre la visita a las doctrinas de religiosos de Chiapas [12 ff.].

AGI, Guatemala, 161, exp. 43 (3). Chiapas, 30 de abril 1679. Al señor presidente [del Real Consejo de Indias]. El obispo don Bravo de la Serna representa los trabajos que ha padecido, los medios para la provincia de Los Zendales a la reducción de los indios, informa de las causas de los oidores de Guatemala, remítese a la relación que hará en esta corte el maestrescuela de aquella iglesia que viene con poderes del cabildo, que se le excuse de la dignidad de obispo por que sólo desea retirarse a la quietud [5 ff.]. AGI, Guatemala, 215. Cartas y expedientes del presidente y oidores de aquella Audencia. Años de 1653 a 1699.

AGI, Guatemala, 215, exp. 2 [3]. [1690] Testimonio de la primera y segunda pregunta de la visita generalde Scals a la provincia de Chiapas [97 ff.].

AGI, Guatemala, 294. Expediente sobre la sublevación y pacificación de 32 pueblos de la provincia de Chiapas. Año de 1712 a 1721 . Legajo 20.

AGI, Guatemala, 294, exp. 23. Ciudad Real, años de 1712 y 1713. Cuaderno $1^{\circ}$. Testimonio de los autos hechos sobre la sublevación de treinta y dos pueblos de indios de los partidos de Los Zendales, Coronas y Chinampas, y Guardianía de Huitiupán de la provincia de Chiapas por el señor don Toribio de Cosío, caballero de la orden de Calatrava, del Consejo de su majestad, gobernador y capitán general de este reino, y presidente de la Real Audiencia de Guatemala, con asistencia de Diego Antonio de Oviedo y Bańos, del Consejo de su majestad, oidor de dicha Real Audiencia, y electo del Real y Supremo de las Indias, y auditor general de guerra, por ante Isidro de Espinosa, secretario de cámara y mayor de gobierno y guerra. Contiene todo lo que diariamente se obró por dicho señor presidente desde el día seis 
de octubre de dicho año de 712 en que resolvió pasar personalmente con asistencia de dicho señor oidor a la pacificación y castigo de dichos pueblos sublevados hasta que conseguida felizmente en el todo tan ardua empresa se restituyó a la ciudad de Guatemala, que fue el día 9 de abril del año siguiente de 1713, y providencias que después se han ido continuando para el entero sosiego de aquella provincia y seguridad en lo venidero [871 ff.]. AGI, Guatemala, 296. Expediente sobre la sublevación y pacificación de 32 pueblos de la provincia de Chiapas. Años de 1712 a 1721. Legajo $4^{\circ}$ y último.

AGI, Guatemala, 296, exp. 9. Ciudad Real, año de 1712. Cuaderno $7^{\circ}$ Testimonios de los autos que se hicieron por la justicia ordinaria y alcalde mayor de Chiapas desde que comenzó la sublevación de los treinta y dos pueblos de los partidos de Los Zendales, Coronas, Chinampas y Guardianía de Huitiupán, hasta que llegó a Ciudad Real a entender personalmente en su pacificación el señor don Toribio de Cosío [...] [272ff.].

AGI, Guatemala, 375. Expediente sobre que se mantenga a la religión de Santo Domingo en las siete doctrinas de la provincia de Los Zendales. 1684-1740.

AGI, Guatemala, 375, exp. 4. Tercera serie de documentos sobre la sucesión en los pueblos de Los Zendales del clero regular por el clero secular. 1721-1740.

AGI, Guatemala, 389. Registros de oficios: Reales órdenes dirigidas a las autoridades del distrito. Años 1684 a 1708.

AGI, Guatemala, 389, exp. 1. Guatemala. De oficio desde 30 de marzo de 1685 hasta 13 de octubre de 1692 [311 ff.].

AGI, Guatemala, 390. Registros de oficios: Reales órdenes dirigidas a las autoridades del distrito. Años 1708-1735.

AGI, Guatemala, 390, exp. 2. Reales cédulas del 14 de septiembre 1715 al 30 de marzo 1720 [486 ff.].

AGI, Guatemala, 390, exp. 3. Reales cédulas del 30 de marzo 1726 al 6 de noviembre 1735 [341 ff.].

AGI, Guatemala, 391. Registros de Oficio. Reales órdenes dirigidas a las autoridades del distrito. Años de 1739-1750. 
AGI, Guatemala, 391, exp. 1. Audiencia de Guatemala. Despachos de oficio desde 1o de marzo de 1739 hasta 31 de octubre de 1742 [376 ff.].

AGI, Guatemala, 935. Expedientes inventariados. 1819.

AGI, Guatemala, 935, exp. 1. [San Lorenzo, 12 de noviembre 1776] Real cédula al presidente de la Audiencia de Guatemala [12 ff.]. AGI, México, 3102. 1774. Yucatán. Expediente sobre la agregación de la provincia de Tabasco en el obispado de Yucatán a la de Ciudad Real de Chiapas.

AGI, México, 3102, exp. 1. Número 11. Primera pieza con 154 fojas [del expediente sobre la agregación de la provincia de Tabasco en el obispado de Yucatán a la de Ciudad Real de Chiapas] [154 ff.].

AGI, México, 3102, exp. 2. [24 de octubre 1766] El obispo y Cabildo de Mérida de Yucatán en consecuencia de la real cédula de 4 de octubre de 1765 da cuenta a vuestra majestad con documentos justificativos de no verificarse las causas que representó el reverendo obispo y Cabildo de Ciudad Real para la agregación de la provincia de Tabasco a su obispado, los gravísimos inconvenients que resultaría de desmenbrarla del obispado de Yucatán y los beneficios que se seguirían de subordinarse la alcaldía mayor de Tabasco al gobierno de Yucatán [16 ff.].

Archivo Histórico Diocesano de San Cristóbal de Las Casas (AHDSC)

AHDSC, Fondo Diocesano, carpeta 1095, exp. 2. [1807-1808] Cuenta y razón de las fiestas, matrimonios y entierros en la parroquia de Ixtacomitán, Ixtapangajoya, Pueblo Nuevo y Solosuchiapa, correspondiente a los años de 1804 a 1808 [18ff.].

AHDSC, Fondo Diocesano, carpeta 3763, exp. 30. 1816. Lista de las cantidades que cada curato contribuye a la sagrada mitra en razón de la cuarta episcopal [1 f.].

AHDSC, Fondo Diocesano, carpeta 3776, exp. 3. [1778]. Informe de los vasallos que tiene su majestad en este obispado de Ciudad Real de Chiapas, inclusos los eclesiásticos seglares y regulares, mujeres, niños y niñas: sacado de las certificaciones o padrones dados por los curas y respecto a los religiosos y su número consta 
de las razones dadas por sus superiores [Borrador del censo del obispo Francisco Polanco] [1778] [4 ff.].

AHDSC, Fondo Diocesano, carpeta 4081, exp. 3. [1856] Estado que comprende el número de eclesiásticos y curatos de la diócesis de Chiapas [2 ff.].

AHDSC, Fondo Diocesano, carpeta 4585, exp. 3.1650 [sic, por 1665]. Real orden para que se dé colación del curato de Teopisca al reverendo padre fray Pedro Román. [16 ff.].

AHDSC, Fondo Diocesano, carpeta 4586, exp. 3. Año de 1673 [sic, por 1663]. Copia simple de la respuesta del ilustrísimo señor doctor don fray Mauro de Tovar a una real provisión que se le notificó sobre colación de curatos en los religiosos dominicos [16 ff.].

AHDSC, Fondo Diocesano, carpeta 4792, exp. 8. Año de 1663. Certificación del escribano real comprensiva del tanto que cada pueblo de esta provincia ha pagado de tributo [7 ff.]. [Antes AHDSC, exp. 23].

AHDSC, Fondo parroquial, caja 10, libro 2, Libro de registro de los despachos de la secretaría episcopal que mandó hacer en 342 fojas el ilustrísimo y reverendísimo señor maestro don fray Francisco Núñez de la Vega de la orden de predicadores, obispo de esta Ciudad Real de Chiapas y Soconusco, del Consejo de su majestad, en 27 de enero de 1684 años [1683-1730].

AHDSC, Fondo parroquial, caja 231, libro 1. Libro de bautizos de Chilón. 

Anexos 



\section{Cuadro 1.}

Prioratos, gUARdianías Y BENEFICIOS Del obispado de Chiapa y Soconusco

(1595-1705) 
Juan Pedro Viqueira Albán

Geografía religiosa del obispado de Chiapas y Soconusco (1545-1821)
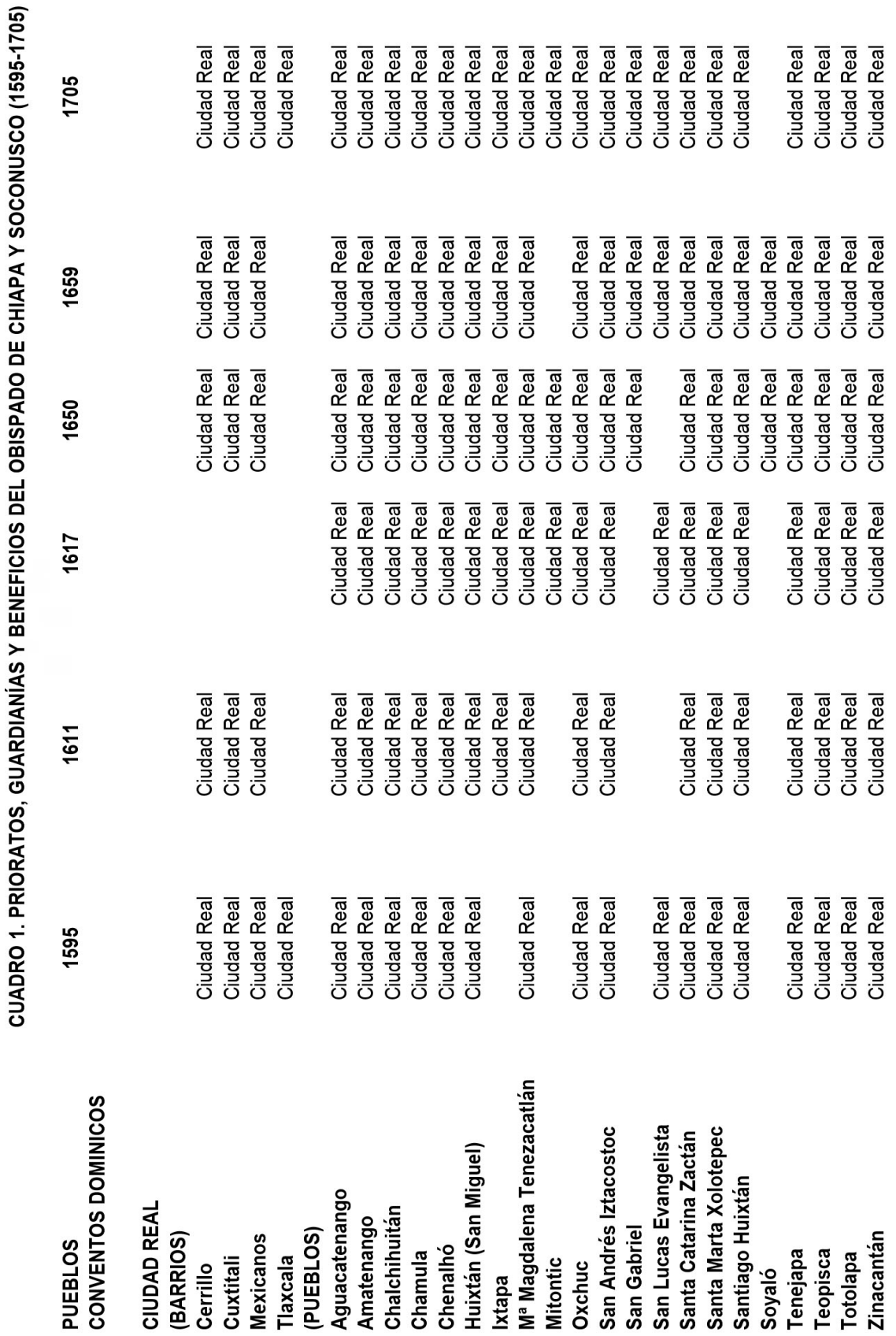

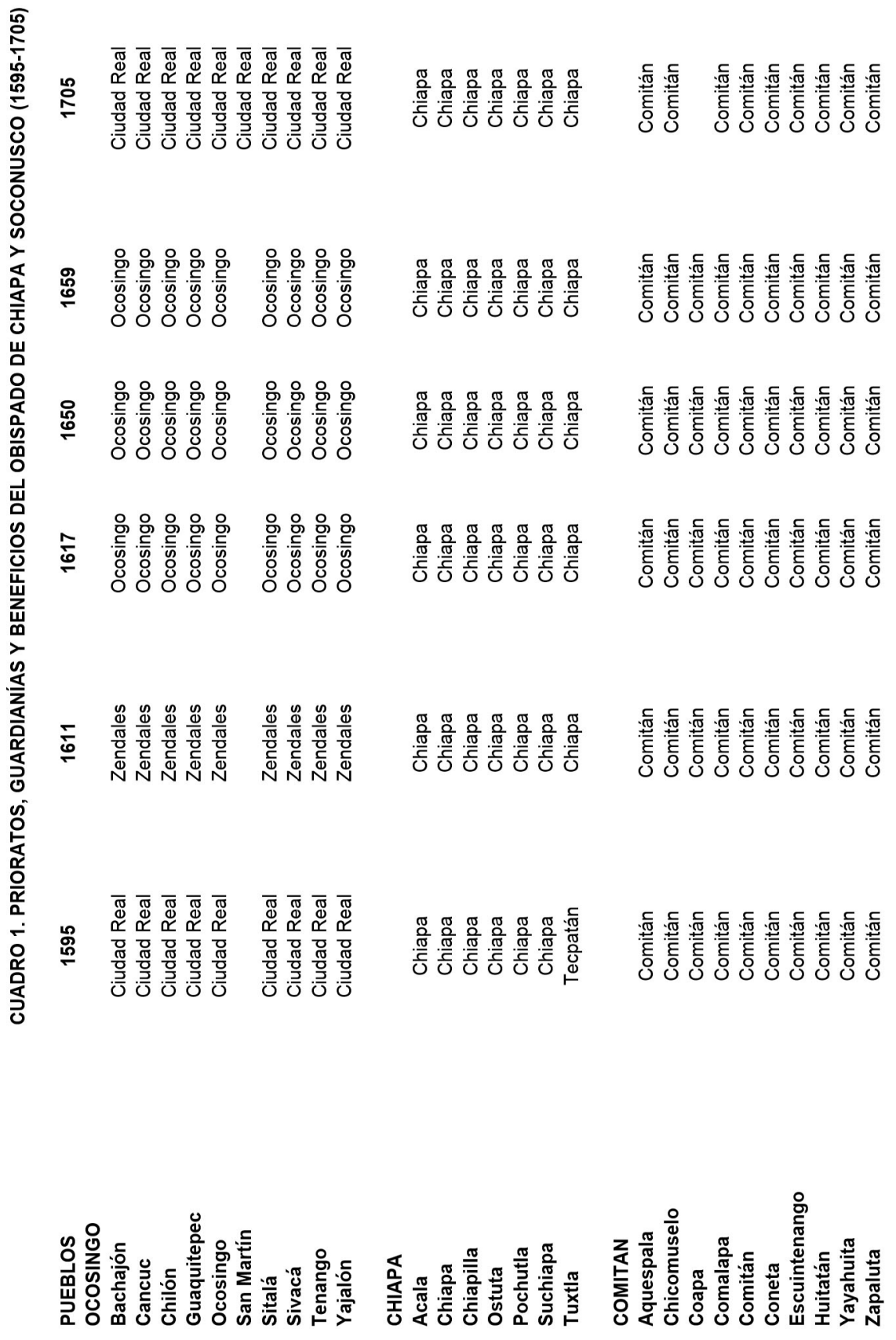


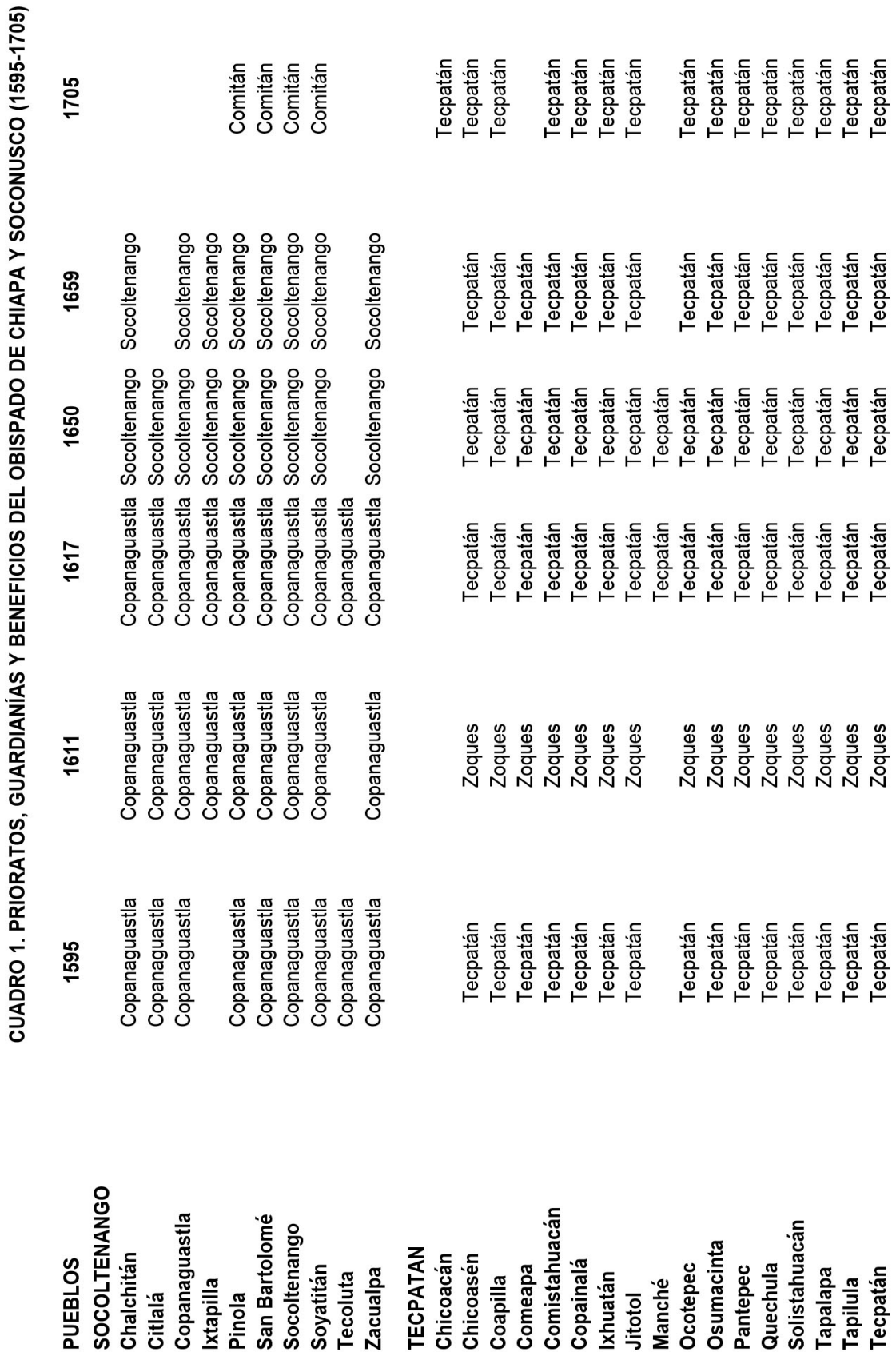




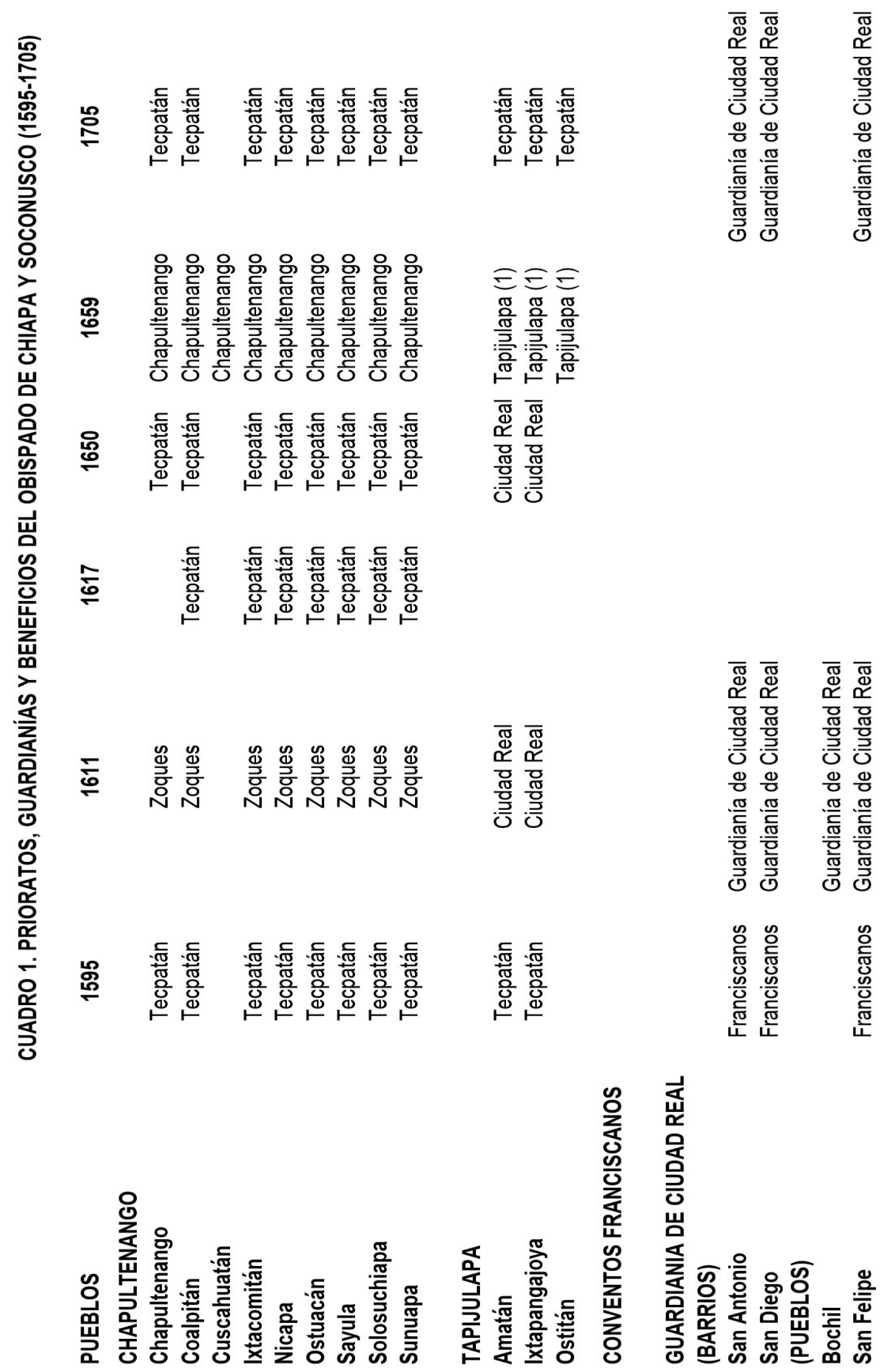



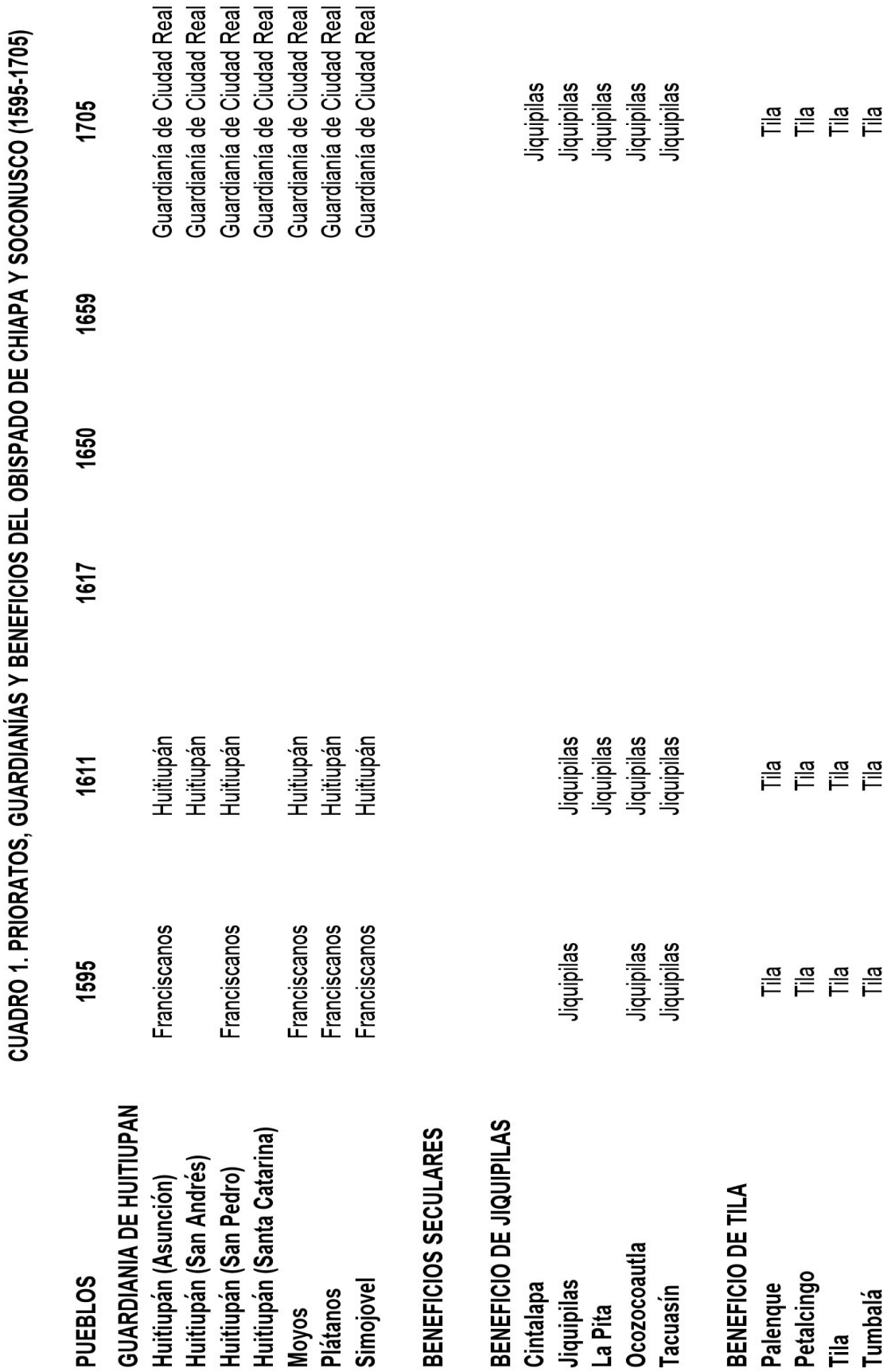
Geografía religiosa del obispado

de Chiapas y Soconusco (1545-1821)

$\stackrel{2}{2}$

哭

용

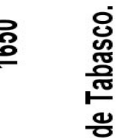

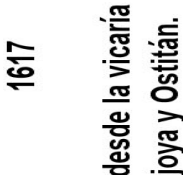

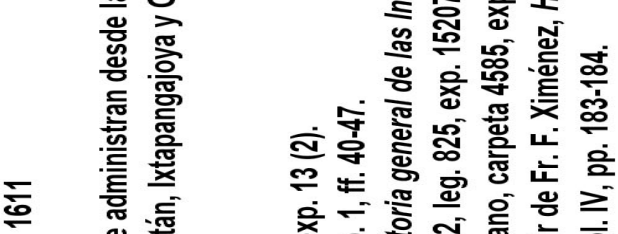

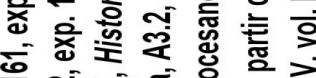

\&

党

흫 홓

的

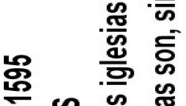

里弯

홍 矛

登

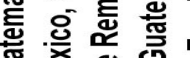

今 迹

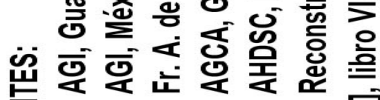

客它出

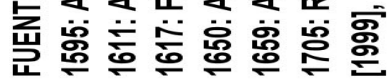

올 

Cuadro 2.

Parroquias del obispado

\section{de Chiapa y Soconusco}

(1656-1830) 


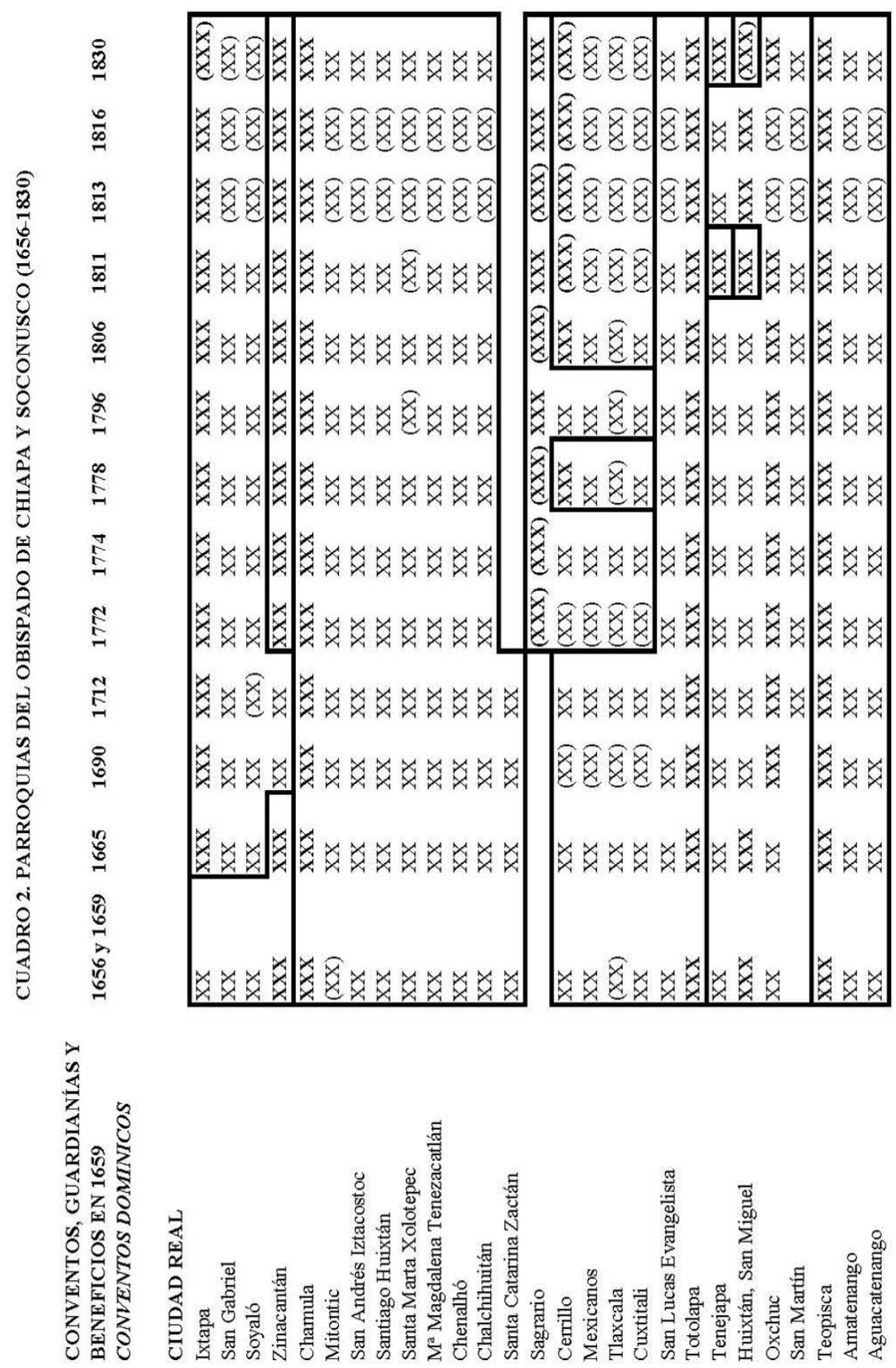




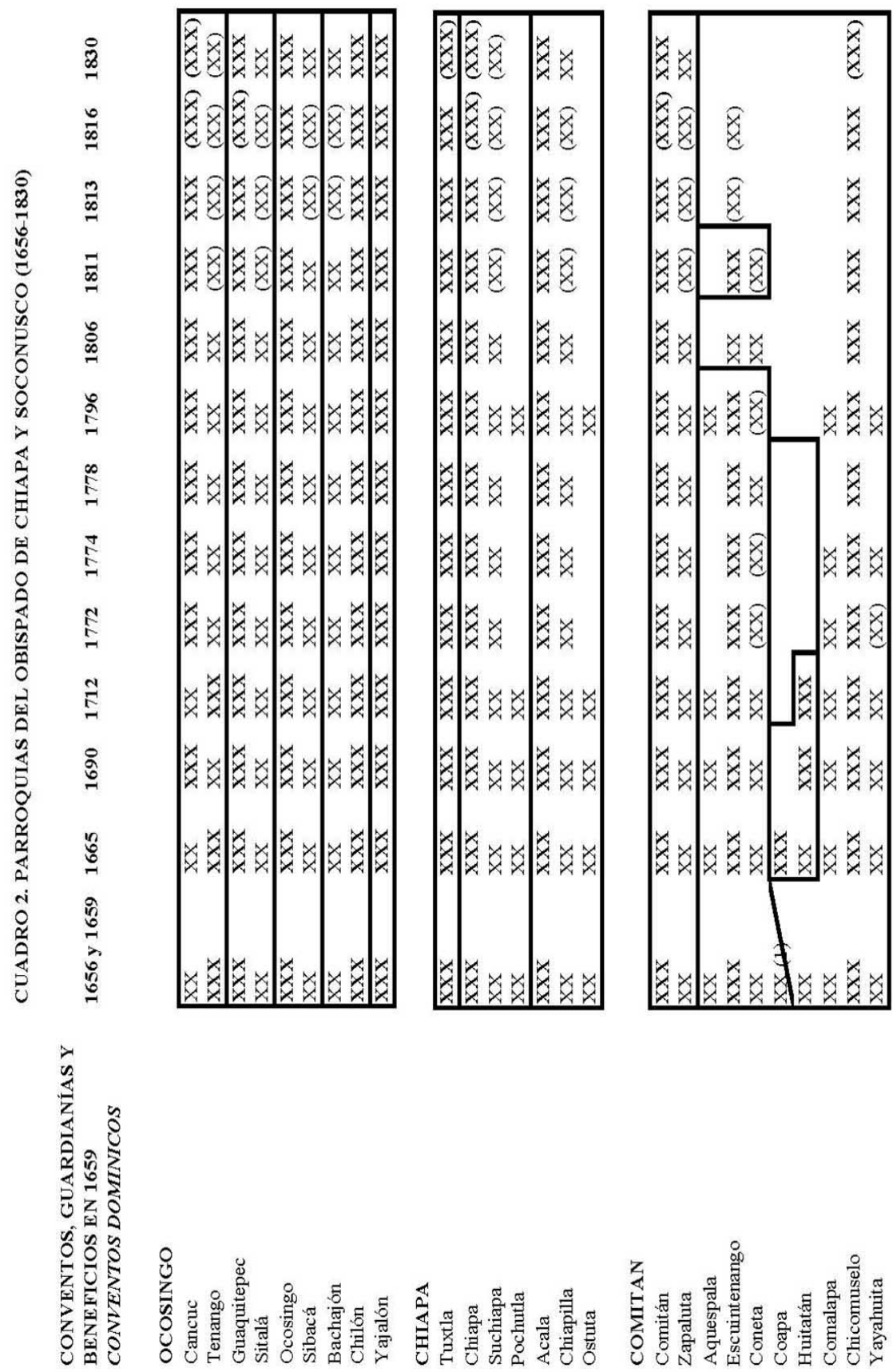




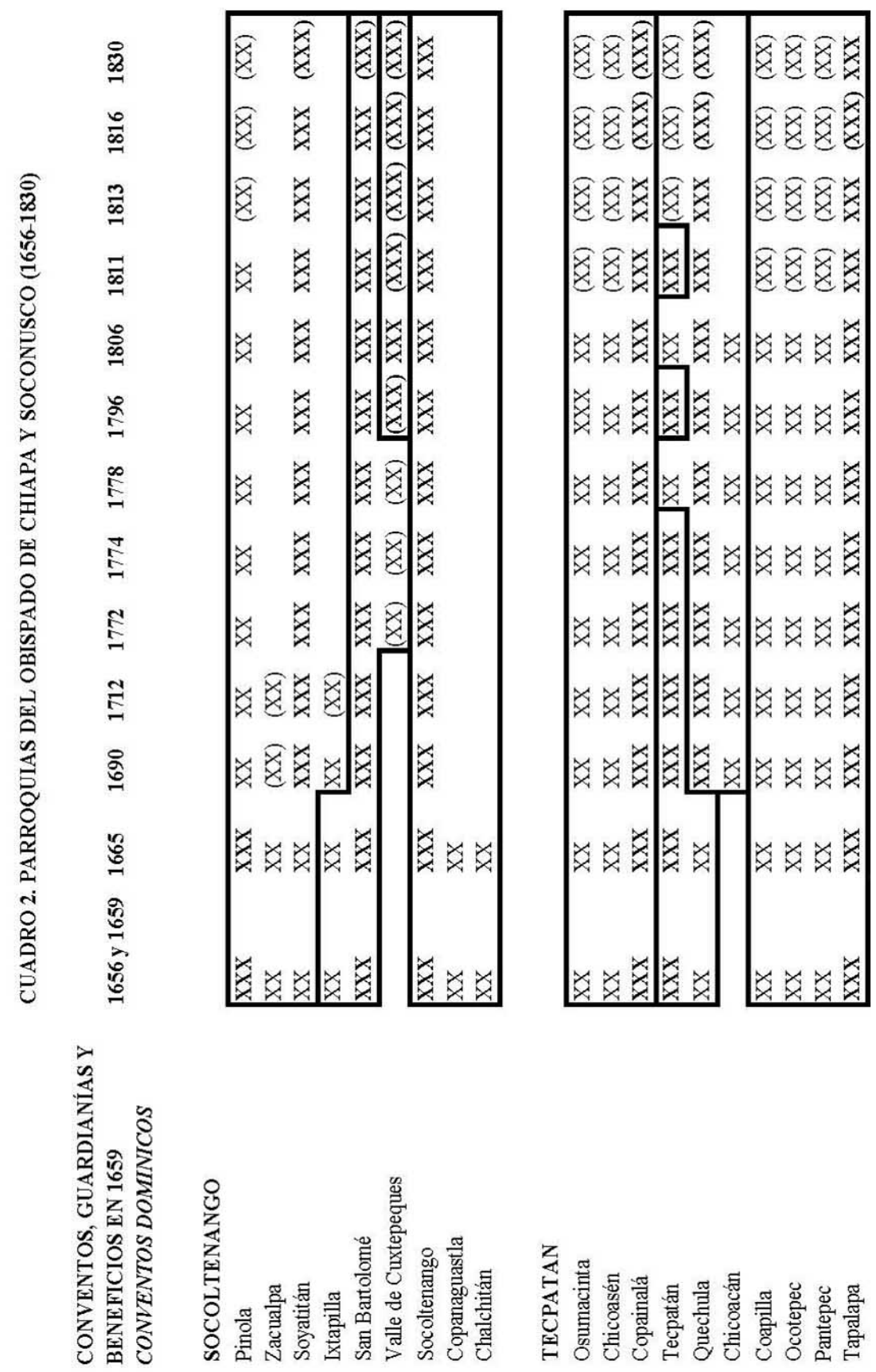



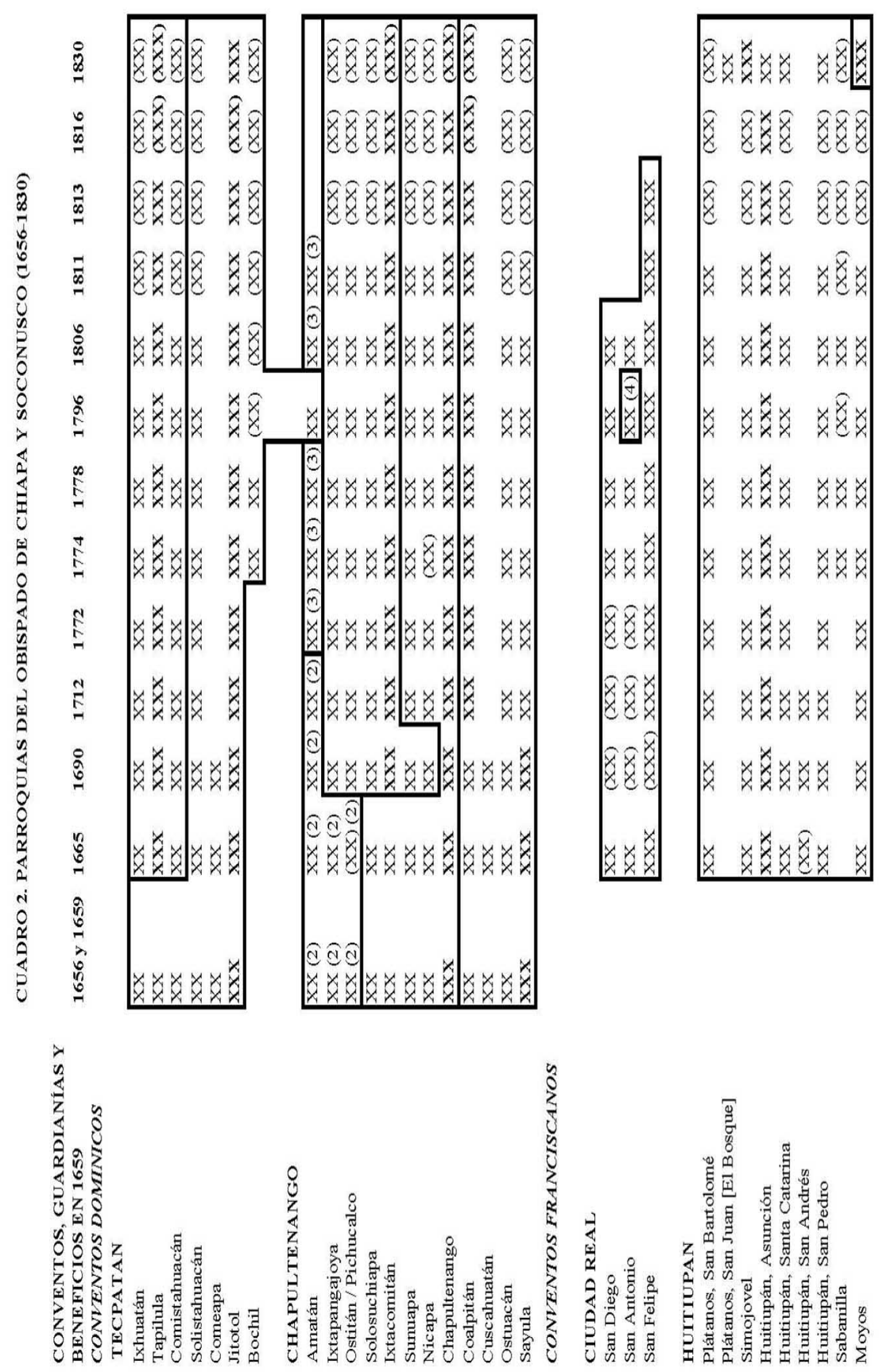

de Chiapas y Soconusco (1545-1821)
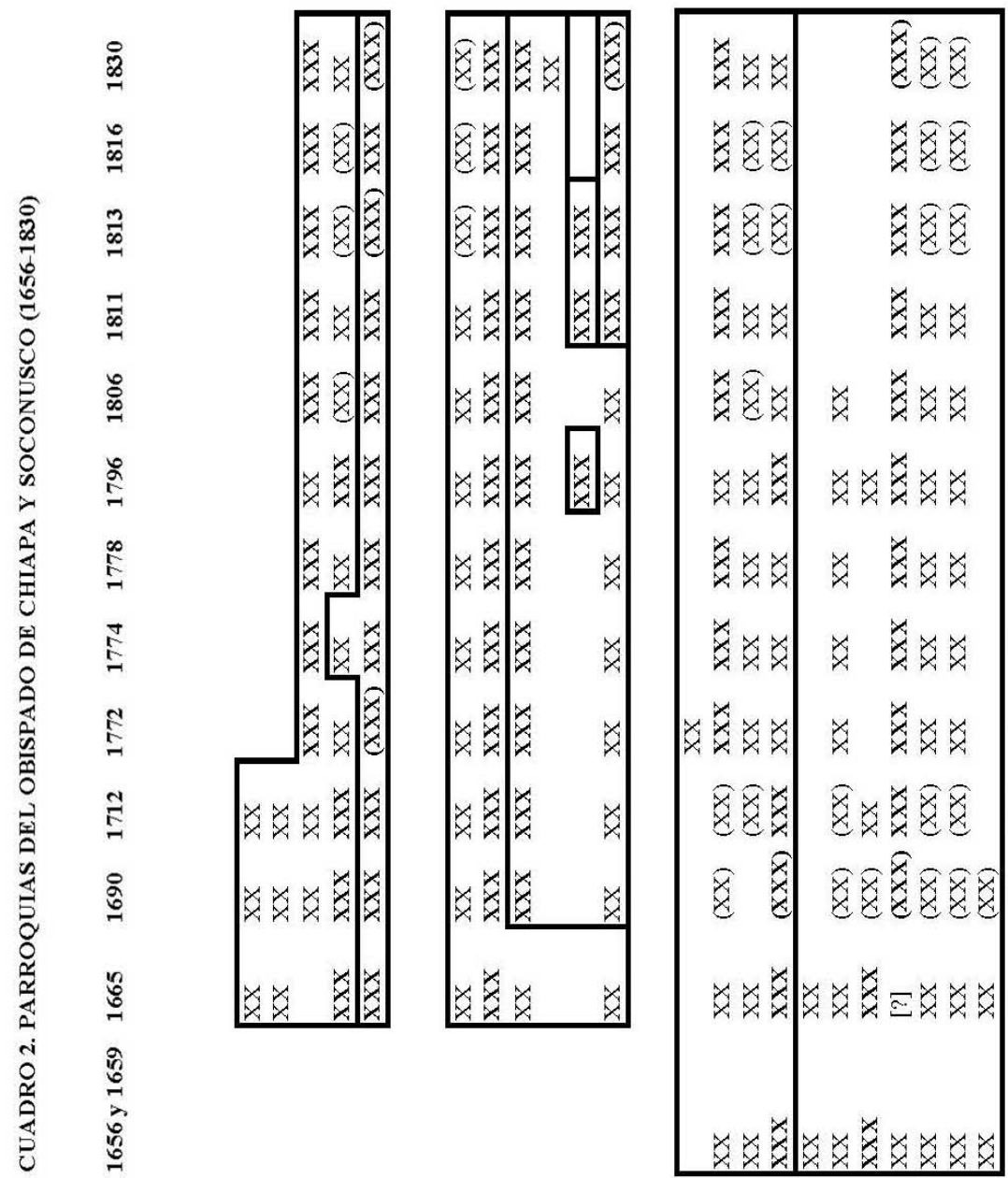

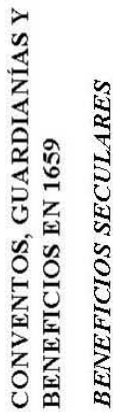
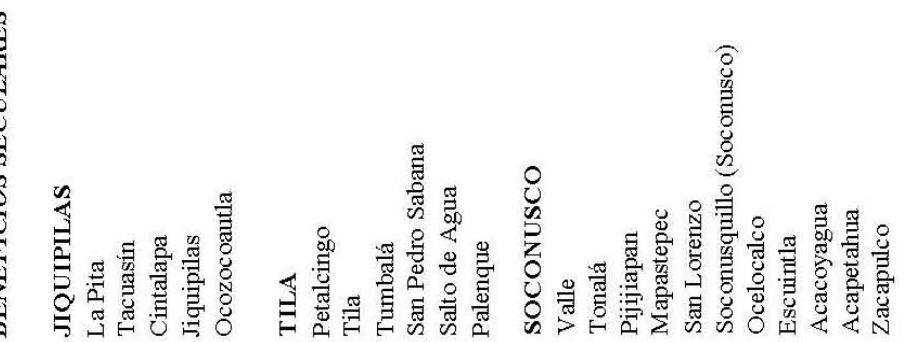


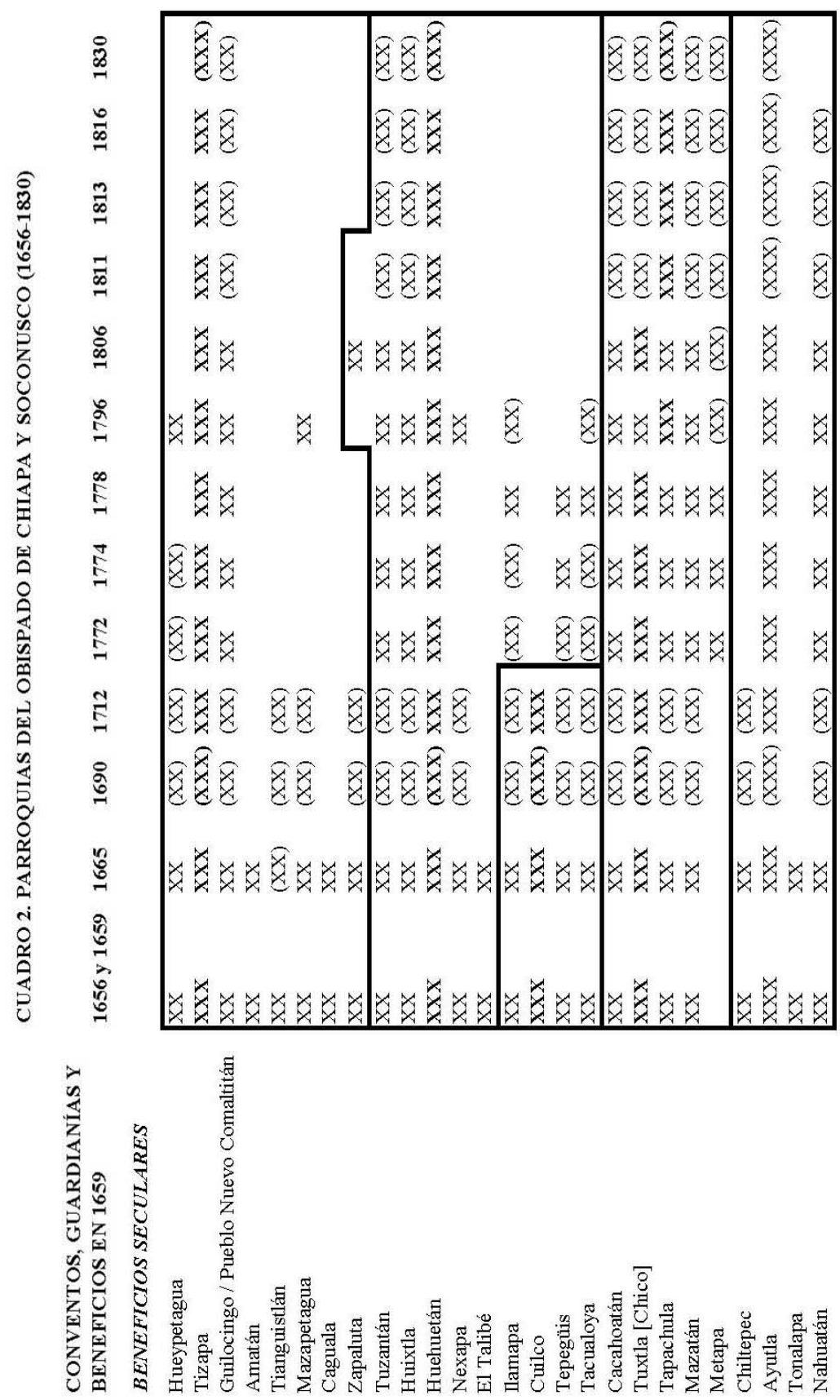




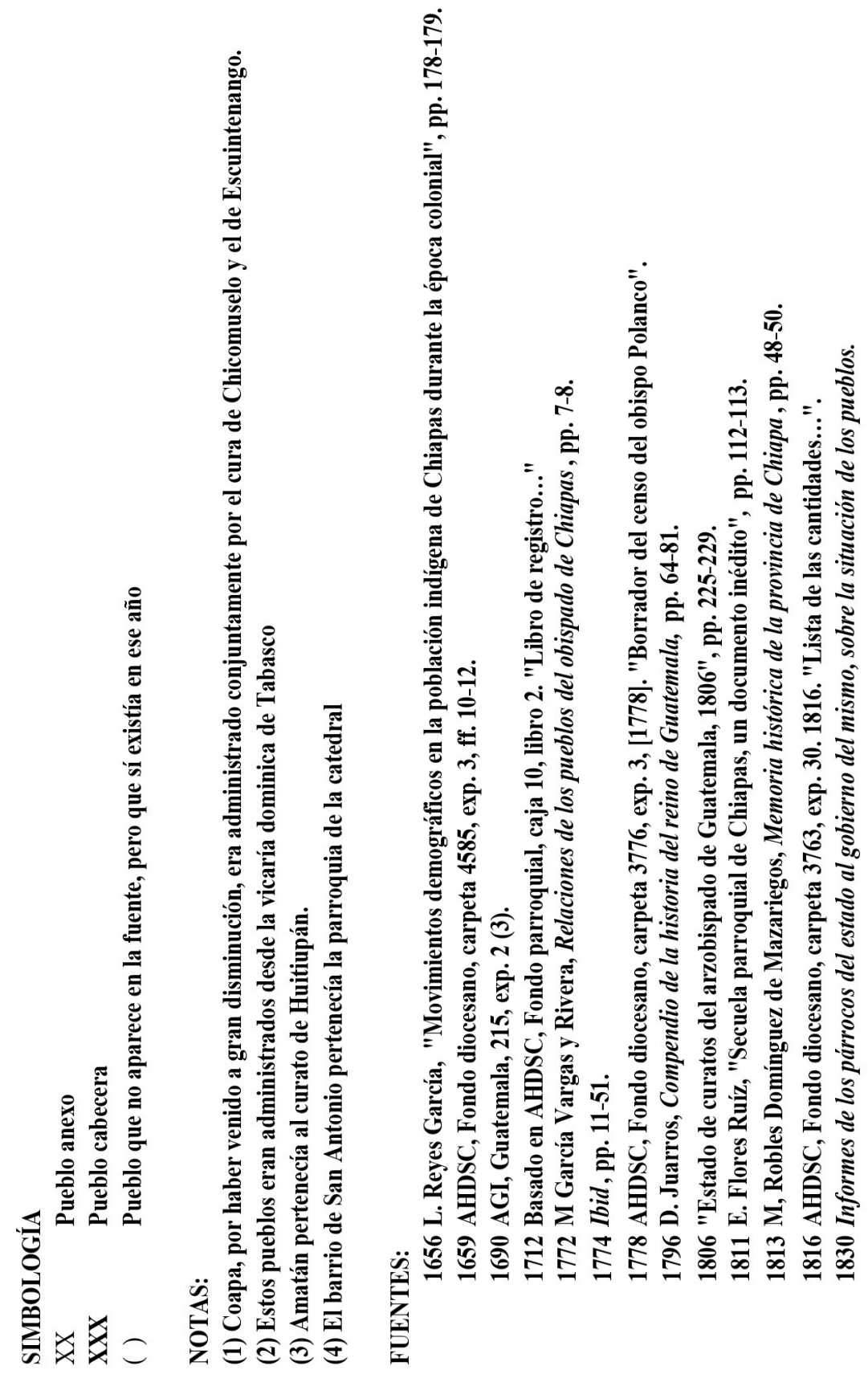




\section{Cuadro 3.}

FECHAS DE LA SECULARIZACIÓN DE LAS DOCTRINAS DEL OBISPADO De Chiapa y Soconusco

$$
\text { (1762-1856) }
$$




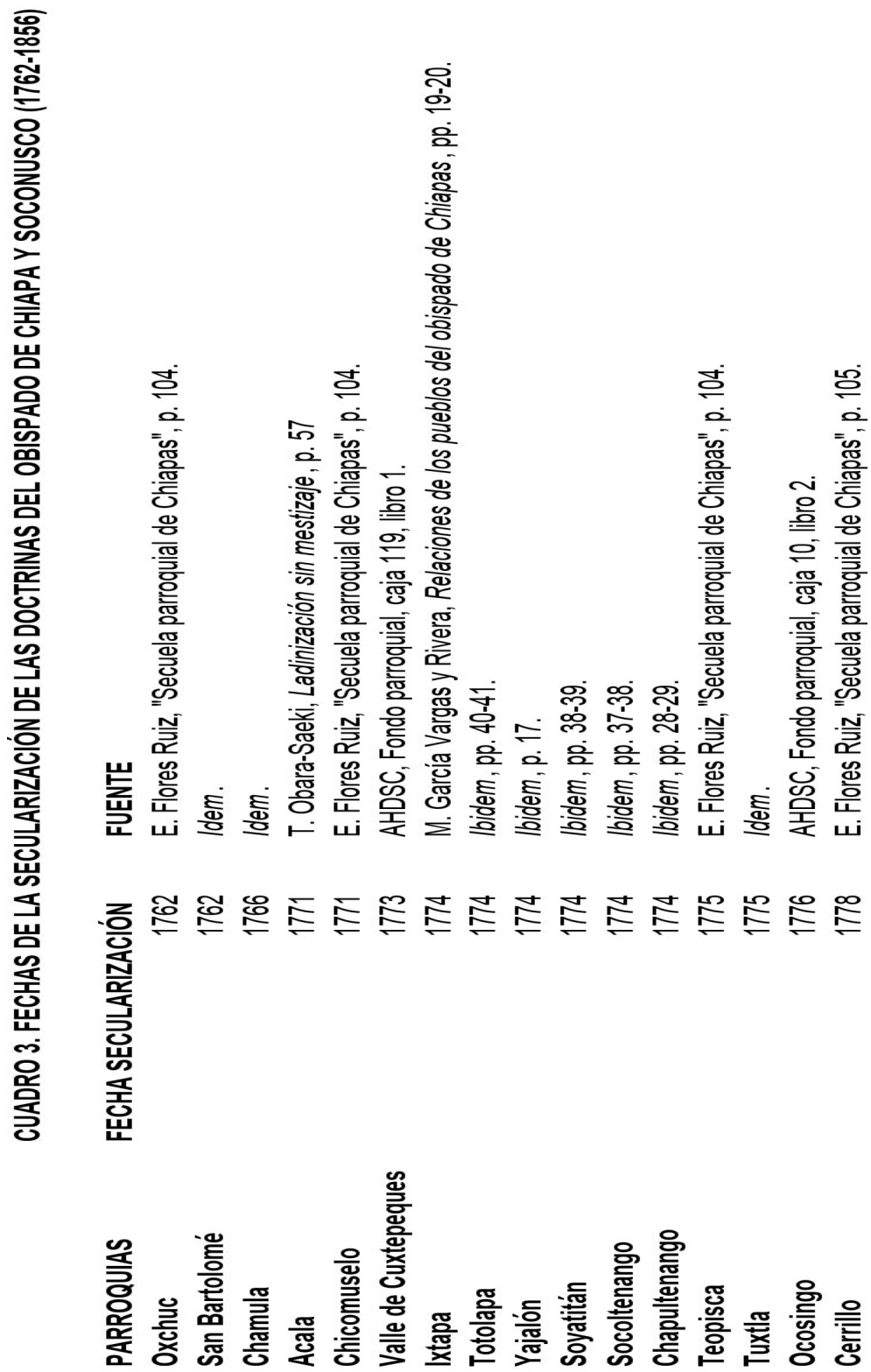




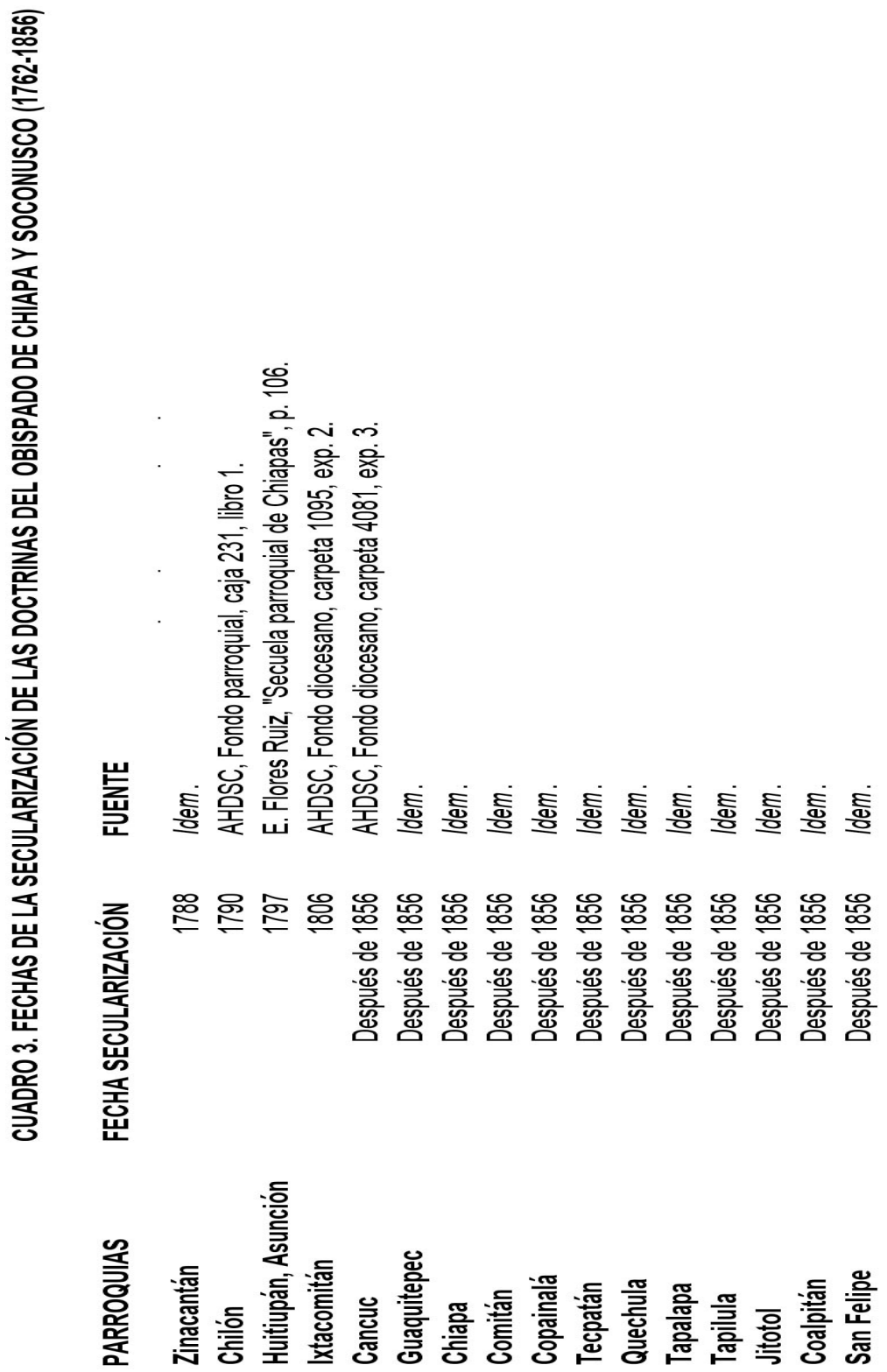

